\title{
Urban Low Emissions Zones A Behavioral Operations Management Perspective
}

\author{
Virginie Lurkin ${ }^{\mathrm{a}, \mathrm{c}}$, Julien Hambuckers ${ }^{\mathrm{b}}$, Tom van Woensel $^{\mathrm{a}}$ \\ ${ }^{a}$ Eindhoven University of Technology, Department of Industrial Engineering Innovation Sciences \\ ${ }^{b}$ University of Liège, HEC Liège \\ ${ }^{c}$ corresponding author, Postbus 5135600 MB Eindhoven, v.j.c.lurkin@tue.nl
}

\begin{abstract}
Environmental traffic restrictions are increasingly implemented in a large number of cities. One popular strategy consists in setting up Low Emission Zones (LEZs) that regulate or restrict the access to a dedicated urban area, for different classes of polluting vehicles. While LEZs are growing in numbers, there is a lack of objective evidence on when and how they actually contribute in reducing air pollution. The main objective of this paper is to show how different LEZ setups lead to different impacts on air pollution. To do so, we use a conceptual framework based on simulated traffic data and behavioral hypotheses. Our analysis highlights that the impact of LEZ on air pollution does not only depend on the severity of the operational rules, but also on its interaction with the behavior adopted by road users, and calls for ex ante considerations of these aspects before establishing the LEZ.

Keywords: Urban Low Emission Zones, pollution, road users behavior
\end{abstract}

\section{Introduction and Motivation}

Two-thirds of the world population will live in cities by 2050 (Nations, 2018). Rising urbanization leads to a rapid increase of passenger and good flows in our limited urban spaces, creating unprecedented issues in terms of urban traffic congestion and air pollution (Savelsbergh and Van Woensel, 2016). The European Parliament resolution of 13 March 2019 on "A Europe that protects: Clean air for all" (2018/2792(RSP)) explicitly urges the Member States to prioritize the implementation of coordinated actions and policies at all levels and in all sectors aimed at improving air quality in cities and urban areas, in order to reach EU air quality goals (...). As a result, many cities around the world are currently adopting unique low-capital strategies to tackle pollution and mitigate climate change. These strategies generally fall into two categories, depending on whether they target the supply or demand side of the transportation system.

On the supply-side, Transportation System Management (TSM) groups supply strategies that are used to increase utilization of the existing road space (Stopher and Stanley, 2014). These solutions aim at increasing the efficiency of a transportation facility without increasing its size. Typical examples are dedicated or priority lanes for high-occupancy vehicles (HOV) or the dynamic conversion of existing lanes (e.g. changing a two-lane street to a three-lane street during peak times). On the demand-side, Travel Demand Management (TDM) looks at possible solutions to shift or reduce the transport demand during congested conditions by 
changing human behavior (Stopher and Stanley, 2014). TDM strategies include, among other things, road pricing, congestion charges, ride-sharing, and positive incentives for sustainable transport modes, such as public transport, cycling, or walking.

An increasingly popular TDM strategy is the establishment of Low Emission Zones (LEZ). These zones regulate or restrict the access to a defined geographical area, generally an urban space, for classes of polluting vehicles. LEZs are part of the wider panoply of Urban Vehicle Access Restrictions (UVAR). They are strongly promoted by the European Commission (The European Commission, 2017). This is considered as highly effective measures that city policy makers can impose to control for the pollution levels. Consequently, LEZs bloom over the years in European cities LEZ, alongside initiatives aiming at reducing air pollution without interfering with the vehicle movements (e.g. actively promoting the acquisitions of more sustainable vehicles) or by directly reducing congestion (e.g. establishing congestion charging zones or road pricing).

Clearly, the main driver for urban policy makers to set up an LEZ is to increase liveability for the inhabitants, mainly in terms of air pollution. The expectation is that air pollution is reduced due to less traffic, or at least due to road users' change of behavior. As a consequence, several cities are planning to introduce LEZs (e.g. 14 major French conurbations will create LEZs in 2020) or to tighter the current restrictions of their existing LEZs (e.g. the current LEZ for diesel vehicles in Brussels will be further tightened in 2020, and also in 2022 and 2025). Increasing the severity of the restrictions, whether by extending the minimum requirement for vehicles, or the operating hours, can certainly help in that matter.

We identify three main dimensions (in short, VAT) for setting up LEZs.

- Vehicle. Depending upon the fuel used (diesel, gasoline, electricity, etc.) and/or engine age, access to the LEZ is limited. Usually, older vehicles (e.g. based on the Euro emissions standards) are banned from the LEZ area, assuming this leads to a better living environment for the inhabitants. In the extreme case, we have a zero-emission zone (ZEZ) where only zero-emission vehicles (e.g. electric vehicles) are allowed. This latter is suggested as a useful local policy for promoting electric vehicles (for goods distribution) in Pelletier et al. (2016).

- Area. The actual geographical region depicted as LEZ is an important dimension. A large number of variations exist, ranging from streets, over neighborhoods, to complete downtown areas.

- Time. This refers to the time period during which the LEZ is "open" for vehicles. Some LEZs do not allow vehicles to enter a given city area during certain periods of time. A straightforward example is when delivery lorries are only allowed to enter before or after the opening hours of the stores in a shopping district (Quak and de Koster (2009)).

Unfortunately, little is known about the impact of road users' reactions to the introduction of LEZs on emissions. Indeed, although road users are expected to drive less, or to change their polluting vehicle for a cleaner one, they might adopt alternative decisions that undermine the efficacy of the LEZs. For example, in Leonhart (2017), 7 out of 88 respondents stated that they would not enter anymore the LEZ if their car was not admitted. 
As a consequence, road users could either use public transportation inside of the LEZ or take a detour to drive around the LEZ. This behavior prevents the acquisition of cleaner vehicles and generates additional emissions via additional use of vehicles, in opposition with LEZs' objectives. While road users' behavior ultimately determines how successful the policy will be, behavioral choices regarding alternative transportation modes and alternative road paths, in the context of a restricted traffic area, remain highly uncertain. Therefore, understanding the conditions of success of an LEZ is crucial for the implementation of an appropriate policy.

While LEZs stimulate lively discussions in the public sphere, most academic studies on the topic adopt an environmental perspective. Yet, there is little doubt that the implementation of such measures is posing a number of operational challenges, both for decisions makers and road users. The main objective of this paper is to show how different LEZ setups, combined with different assumptions regarding road users' behavior, lead to significantly different impacts on air pollution. The main contributions are as follows.

1. We introduce a conceptual framework based on simulations to investigate the impact of the VAT dimensions of a LEZ on air pollution reductions.

2. We include road users' behavior in our analysis, and discuss the implications of choices like bypassing the zone on the success of LEZs. Doing this, we recognize the risk that LEZs could simply move the problem of air pollution outside the targeted area. To take that risk into account, we analyze the impact on air pollution not only within the zone, but also investigate the possible consequences on the surrounding area.

3. The important key observations are as follows. Increasing the number of affected vehicles does not necessarily increase the achievable emissions gains. In some cases, imposing an LEZ might even be counterproductive and actually lead to higher emissions than the case without an LEZ. This is especially true when the driver behavior is ignored, but also strongly relates to the VAT dimensions discussed above.

The remainder of this paper is organized as follows. Section 2 presents a non-exhaustive list of former studies on LEZs. Section 3 gives an overview of the different LEZs existing in Europe and discusses their three main design dimensions. In Section 4, we explain our simulation framework, including how we generated our data and how we constructed different user behavior scenarios for our experiments. Section 5 gives empirical results. Section 6 discusses policy implications. Section 7 ends the paper with conclusions.

\section{Former Studies on LEZs}

LEZs have been studied from different perspectives. In particular, a large body of literature exposes the principal findings of ex-post studies on the impact of LEZs in European countries. Among others, Ellison et al. (2013) find that the concentration of PM10 within the LEZ in London has dropped by between 2.46 percent and 3.07 percent compared to just over one percent for areas near London but outside the LEZ, an effect much smaller than the one expected in Carslaw and Beevers (2002). More significant reduction of PM10 and NO2 concentrations were observed in Lisbon (Santos et al., 2019, Ferreira et al., 2015) 
and reductions in NOX and PM2.5 were also observed in 5 Dutch cities (Boogaard et al., 2012) following the introduction of LEZs. Holman et al. (2015) focus on five EU countries (Denmark, Germany, the Netherlands, Italy and UK) and conclude that only the LEZs in Germany led to significant (but rather small) positive results in terms of pollutant reduction, a conclusion also reached in Jiang et al. (2017) and Fensterer et al. (2014). Pasquier and Andre (2017) consider London, Lisbon, Stockholm, as well as several German, Dutch, and Italian cities and conclude that most of the time the major expectation needed to achieve EU limit values were not observed. The Norwegian Institute of Transport Economics recently published a review of peer reviewed articles and open web articles dealing with the analysis of LEZs (The European Commission, 2017). They also report mixed results, with some improvements on air quality observed in some studies, and a lack of statistical evidence of air pollution decreases in others.

The conclusions of these studies vary, partly due to methodological challenges, such as data limitations for vehicle emission factors (The European Commission, 2017). However, the heterogeneity of LEZs impacts can be also attributed to other factors like the diversity of pre-LEZ situations (e.g., fleet composition, accessibility to alternative transport modes, or bypass capacity), the LEZ setups, as well as the different behavioral changes induced by those LEZs: among others, Haakman et al. (2020) highlight the importance of the interaction between policy instruments like LEZs and political resistance of road users for successful emissions reductions. André et al. (2017), Flämig et al. (2019) and Ellison et al. (2013) call attention to the importance of local fleet specificities on LEZ efficiency, whereas Borger and Proost (2013) discuss the risk of suboptimal investment in proper infrastructures like bypassing capacity.

Thus, these studies highlight a need for additional insights into the impact of LEZs design and road users' reactions. The present paper aims precisely at shedding light on this issue by means of simulation experiments. Before describing our simulation framework in Section 4, we discuss in more details the design dimensions of LEZs in the next section.

\section{Design Dimensions of Low Emissions Zones}

The first LEZ was introduced in Stockholm in 1996. Following the Swedish example, many European cities implemented similar measures. As depicted in the second column of Table 1, more than $250 \mathrm{LEZs}$ are currently active or planned within European cities. Italy and Germany are by far the most enthusiastic countries, with 107 and 82 LEZs respectively in place. There is currently no harmonized framework regarding the operations of LEZs. For some countries, there is even no national LEZ framework. As depicted in the third column of Table 1, this is the case for Belgium, Greece, Italy, Poland and Portugal. While other countries do have a national framework in place, this scheme does not necessarily imply that cities have to follow the same operational rules. For example, the German national framework sets out the emissions classes and main rules that can be used, but the cities keep the freedom to decide whether, where and when to establish a LEZ.

Looking at these LEZs, we identified three main design dimensions for setting up LEZs: Vehicle, Area and Time (in short,VAT). In what follows, we give more details on each dimension. 
Table 1: European Low Emission Zones

\begin{tabular}{lll} 
Country & $\begin{array}{l}\text { Number } \\
\text { of LEZs }\end{array}$ & $\begin{array}{l}\text { National LEZ } \\
\text { framework }\end{array}$ \\
\hline Austria & 7 & Yes \\
Belgium & 3 & No \\
Czech Republic & $2^{*}$ & Yes \\
Denmark & 4 & Yes \\
Finland & 1 & Yes \\
France & 5 & Yes \\
Germany & $\mathbf{8 2}$ & Yes \\
Greece & 1 & No \\
Italy & $\mathbf{1 0 7} * *$ & No \\
Netherlands & $14^{* * *}$ & Yes \\
Norway & 2 & Yes \\
Poland & 1 & No \\
Portugal & 1 & No \\
Spain & $3^{* * * *}$ & Yes \\
Sweden & 8 & Yes \\
UK & $15^{* * * * *}$ & Yes \\
\hline Total & $\mathbf{2 5 7}$ &
\end{tabular}

Source: http://urbanaccessregulations.eu.

*incl. Prague - Access Regulation - Lorry LEZ. ${ }^{* *}$ incl. A12 Motorway (Tirol) LEZ. ${ }^{* * *}$ incl. Rotterdam Dock - AR/LEZ LEZ. ****incl. Madrid - LEZ Parking LEZ. ${ }^{* * * * * i n c l . ~ L o n d o n ~ C l e a n ~ B u s ~ Z o n e s ~ L E Z . ~}$

\section{Vehicle}

The requirements for vehicles entering a LEZ are generally based on Euro emissions standards (also known as the EURO emissions classes). These standards define the acceptable limits for exhaust emissions of new vehicles sold in the European Economic Area (EEA). Euro standards are determined based on the vehicle category (e.g. passenger cars or commercial vehicles $(\mathrm{CVs}))$, the fuel type and the vehicle's first registration date.

The existing zones are characterized by different rules regarding the required emissions standards of allowed vehicles. For example, Brussels prohibits EURO 2-standard diesel vehicles and EURO 1-standard petrol vehicles or petrol vehicles without a EURO standard, while only Diesel Euro 4 and Petrol Euro 1 vehicles are allowed to drive in Berlin. The decision regarding the vehicles affected by the ban also largely differs across the existing LEZs. For example, all vehicles, light and heavy, petrol and diesel are targeted by the Lisbon LEZ, while only heavy, diesel-powered lorries and buses are currently affected by the ban in Stockholm.

Area

The size of LEZs varies significantly. In Vienna, for example, the ban covers the whole city and spreads out over $414 \mathrm{~km}^{2}$. This is equivalent to the complete city area. In Berlin, the LEZ in the inner city covers $88 \mathrm{~km}^{2}$ (over a total of $891 \mathrm{~km}^{2}$ ) but impacts one third of inhabitants. In London, the current central LEZ is $21 \mathrm{~km}^{2}$ (of a total of $1,583 \mathrm{~km}^{2}$ ), but an expanded LEZ is planned to be $379 \mathrm{~km}^{2}$. Much smaller LEZs exist, too. For example, 
Rome and the historic city centre of Milan have LEZs of $5.5 \mathrm{~km}^{2}$ (of 1,285 $\mathrm{km}^{2}$ ) and $8 \mathrm{~km}^{2}$ (of $181 \mathrm{~km}^{2}$ ), respectively.

Time

Another important difference among the existing LEZs is their operating hours. In some cities (e.g. all the German ones), the LEZs operate 24 hours a day, every day of the year. In other cities, the ban is only effective during a certain time of the day and can vary according to the day of the week and/or the time of the year. In Paris, for example, the ban applies on weekdays from 8:00 to 20:00 for light duty vehicles, and every day from 8:00 to 20:00 for heavy duty vehicles. Other typical examples are the winter LEZs in the Italian regions of Emilia-Romagna, Lombardy, Piedmont and Venice that are active from 1 October to 31 March from Monday to Friday (8:00 to 19:00).

\section{Scenario-based Simulation Framework}

In this section, we present the simulation framework to investigate the impact of alternative LEZ designs, combined with different scenarios of road users' behavior, on the LEZ ability to improve air quality both in and around the restricted zone. Our simulation framework builds around the VAT design dimensions and a number of user behavior scenarios.

\subsection{VAT dimensions}

The area under consideration in this paper is abstracted as a circular LEZ, representing a percentage of a larger region, defined as a square area centered around the LEZ. Doing so, we are able to analyze air pollution within the zone and its surroundings. Moreover, as illustrated in Figure 1, we consider three different LEZ sizes, covering respectively 15\%, 30\% and $40 \%$ of the larger region.
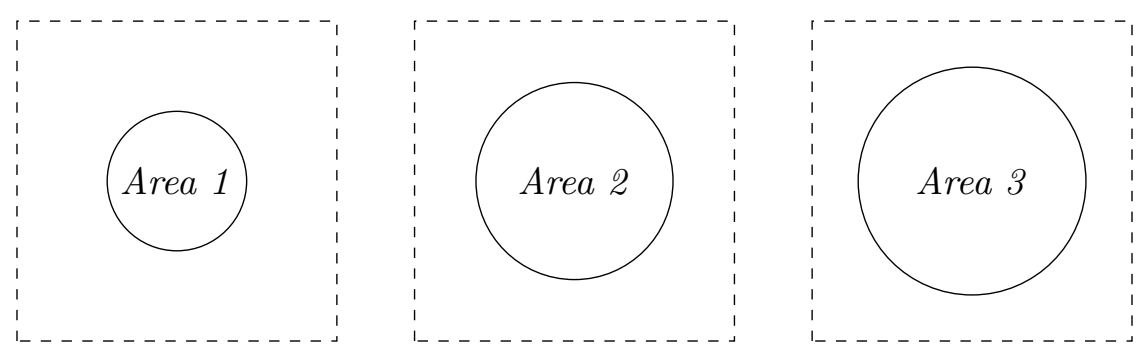

Figure 1-The LEZ areas and the surrounding region

Figure 2 shows how we defined the vehicle and time dimensions. Four vehicle categories and six EURO classes are considered in our study. Regarding the operations hours, we define 24 hourly time periods. In our experiments, different scenarios assume different levels for minimum emission standards, and different time windows for operation hours, i.e. different time periods during which the affected vehicles are not allowed to enter. 


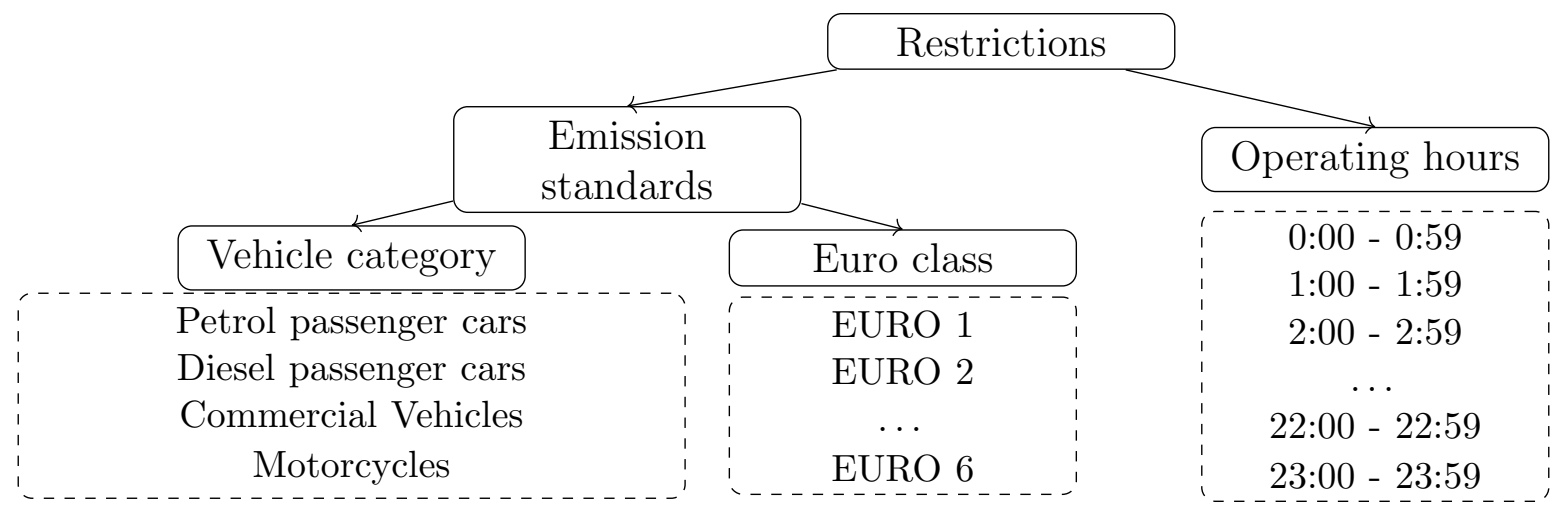

Figure 2-Scenario tree structure for Vehicle and Time

\subsection{Trip generation}

To keep the analysis and the simulations tractable, we focus our analysis on a single day, and consider that 5,000 individual trips occur during that day. We use Algorithm 1 to generate the characteristics of these trips.

Algorithm 1 Generation of individual trips

For $i=1$ to 5,000:

1. Generate random coordinates $\left(x_{i}^{O}, y_{i}^{O}\right)$ and $\left(x_{i}^{D}, y_{i}^{D}\right)$ for trip origin and destination.

2. Determine case $s_{i}$.

3. Generate vehicle category, category $_{i}$, and Euro class, class $_{i}$, based on distributions $\mathbf{D}_{\text {categories }}$ and $\mathbf{D}_{\text {classes }}$.

4. Generate departure time, dtime ${ }_{i}$, based on traffic distribution $\mathbf{D}_{\mathbf{T O D}}$.

In Steps 1.(a) and 1.(b), the origin and destination points, with coordinates $\left(x_{i}^{O}, y_{i}^{O}\right)$ and $\left(x_{i}^{D}, y_{i}^{D}\right)$, can fall anywhere within the square area under study, creating 5 possible cases, as illustrated on Figure 3. The first four cases involve trips that cross the LEZ, either fully, like in case 1, or partially, like in cases 2, 3 and 4. Unlike the other cases, case 5 corresponds to trips that do not cross the LEZ.

In Step 1.(c), the vehicle category and Euro class are attributed based on the probability distributions $\mathbf{D}_{\text {categories }}$ and $\mathbf{D}_{\text {classes. }}$ In our case, we used the UK Vehicle Licensing Statistics data set $^{1}$ to retrieve the distribution among vehicles categories and Euro classes. More specifically, the distribution among vehicles categories (i.e. passenger cars, commercial vehicles, and motorcycles) is based on the number of these vehicles in the UK in 2019. For passenger cars, the subdivision by engine type is based on the numbers provided by the European Automobile Manufacturers Association (ACEA, 2018) that reports around 60\% of petrol cars and around $40 \%$ of diesel cars in UK. Since the vast majority of Commercial Vehicles are diesel (more than 96\%) and almost all motorcycles are petrol, these two categories

\footnotetext{
${ }^{1}$ https://www.gov.uk/government/collections/vehicles-statistics
} 
are not further divided by engine type. The resulting distribution is given on Figure 4 . The Euro class distribution, depicted in Figure 5, is constructed based on the class vehicle age.

Finally, in Step 1.(d), a trip departure time is generated based on the probability distribution of traffic flows per time of day (TOD), $\mathbf{D}_{\text {TOD }}$. The distribution used in this study is showed on Figure 6 and corresponds to the distribution of motor vehicle traffic by time of day on all roads in the $\mathrm{UK}^{2}$.
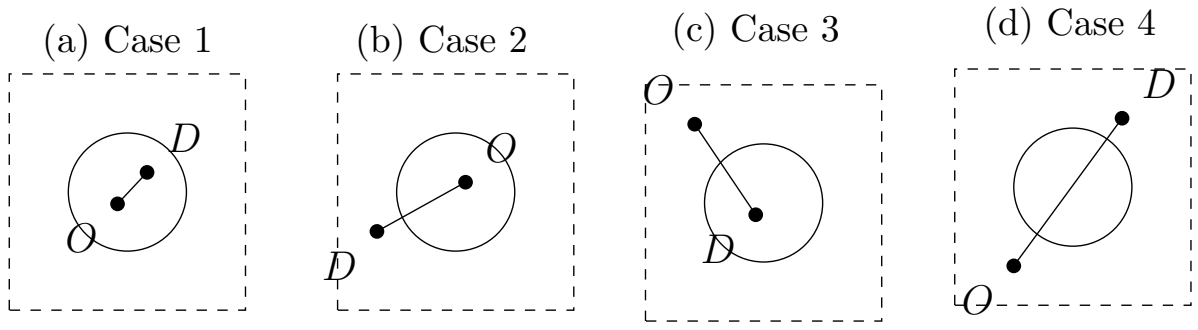

(e) Case 5

Figure 3-Different possible OD pairs

\subsection{Behavior scenarios $(B S)$}

The extent to which a LEZ is fulfilling its emission gain promises also depends on the behavior of the affected road users. More specifically, when a permanent LEZ is established (i.e. for RR1, RR2, and RR3), the affected drivers have two options:

1. Substitute. If the ban applies to all polluting vehicles, only Zero-Emission Vehicles (ZEVs) can be used as substitutes. We assume a ZEV (whether a new one bought by

\footnotetext{
${ }^{2}$ https://www.gov.uk/government/statistical-data-sets/road-traffic-statistics-tra
}

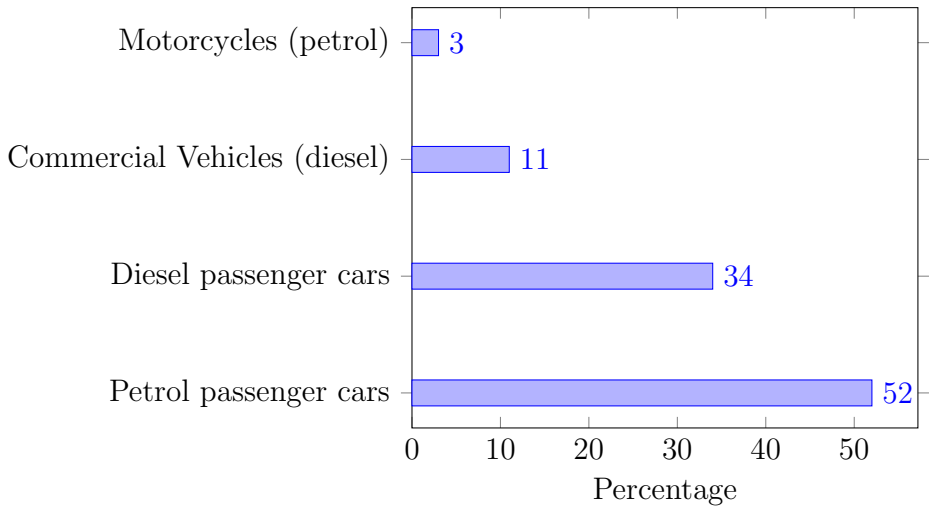

Figure 4-Vehicle category distribution $\mathbf{D}_{\text {categories }}$.

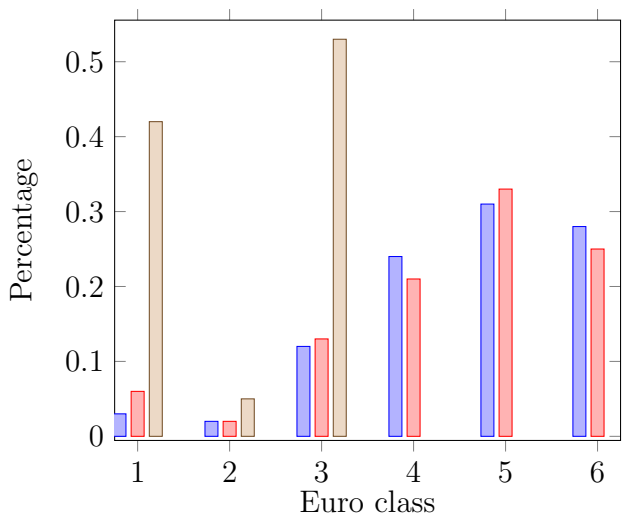

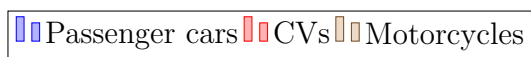

Figure 5-Euro class distribution

$\mathrm{D}_{\text {classes }}$. 


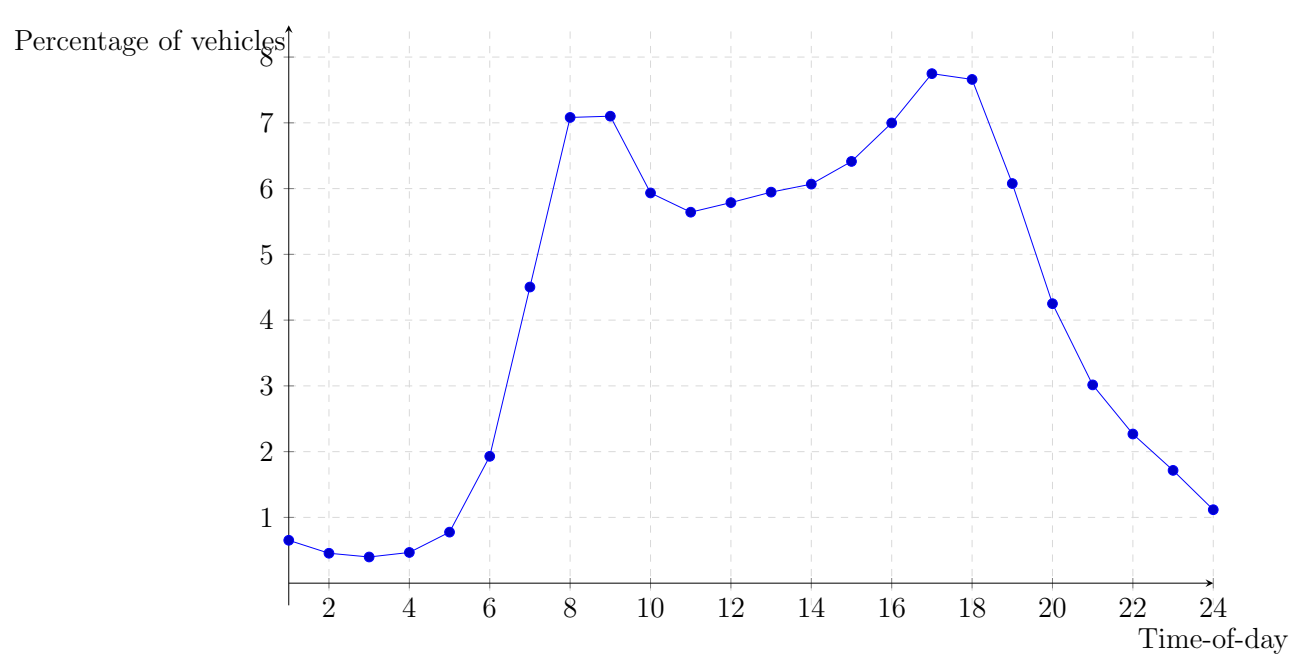

Figure 6-Vehicle traffic distribution by time of day, $\mathbf{D}_{\text {TOD }}$.

the driver or a public one) is always used as a substitute once the decision to change vehicle is made. As depicted in Figure 7 (a), this substitution can be applied to:

(a) The entire trip (e.g. affected drivers buy a zero-emission vehicle and use it to travel from their origin to their destination). This is behavior scenario 1 (BS1).

(b) To the part of the trip that falls within the LEZ (e.g. the affected drivers park their polluting vehicle in a park and ride parking and then use publicly available zero-emission vehicles). This is behavior scenario 2 (BS2).

2. Bypass. In this case, the vehicle makes a detour and entirely bypasses the zone (plus driving longer distances). Figure 7 (b) shows our behavior scenario 3 (BS3) that includes the bypassing behavior.

\begin{tabular}{|c|c|c|c|c|}
\hline \multicolumn{2}{|c|}{$\begin{array}{c}\text { Change } \\
\text { vehicle to ZEV }\end{array}$} & \multirow[t]{2}{*}{$\begin{array}{l}\text { Bypass } \\
\text { the LEZ }\end{array}$} & \multirow[t]{2}{*}{$\overleftarrow{\text { yes }}$} & \multirow{2}{*}{$\begin{array}{c}\text { Trip origin and desti- } \\
\text { nation outside LEZ? } \\
\qquad \downarrow \text { no }\end{array}$} \\
\hline 九 & 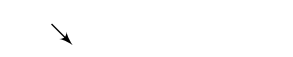 & & & \\
\hline $\begin{array}{l}\text { Entire trip } \\
\quad(\mathrm{BS} 1)\end{array}$ & LEZ only (BS2) & & & $\begin{array}{l}\text { Use ZEV } \\
\text { in LEZ }\end{array}$ \\
\hline
\end{tabular}

(a) BS1 and BS2

(b) $\mathrm{BS} 3$

Figure 7-behavior scenarios for permanent LEZs

3. Change departure time. When the LEZ does not operate 24 hours a day (i.e., non-permanent driving bans), the drivers of the banned vehicles have the additional option to change the departure time to avoid the LEZ during its operating hours. We assume that drivers are willing (and able) to change their departure time by at most 1 hour. Two behavior scenarios (BS4 and BS5) include changing departure time and are illustrated in Figure 8 (a) and (b). 


\begin{tabular}{|c|c|c|c|c|}
\hline & & $\begin{array}{l}\text { Bypass } \\
\text { the LEZ }\end{array}$ & $\overleftarrow{\text { yes }}$ & $\begin{array}{l}\text { Trip origin and destina- } \\
\text { tion outside the LEZ? }\end{array}$ \\
\hline $\begin{array}{c}\text { Change } \\
\text { departure time } \overleftarrow{\text { yes }}\end{array}$ & $\begin{array}{c}\text { Departure time within } \\
1 \text { hour from end of } \\
\text { operating hours? } \\
\downarrow \text { no }\end{array}$ & $\begin{array}{c}\text { Change } \\
\text { departure time }\end{array}$ & $\overleftarrow{\text { yes }}$ & $\begin{array}{c}\downarrow \text { no } \\
\text { Departure time within } \\
1 \text { hour from end of } \\
\text { operating hours? } \\
\downarrow \text { no }\end{array}$ \\
\hline & $\begin{array}{c}\text { Use ZEV } \\
\text { in LEZ }\end{array}$ & & & $\begin{array}{c}\text { Use ZEV } \\
\text { in LEZ }\end{array}$ \\
\hline
\end{tabular}

(a) $\mathrm{BS} 4$

(b) BS5

Figure 8-behavior scenarios for time-limited LEZs

\subsection{Measuring air pollution}

Most of the air quality management plans focus mainly on measures designed to reduce people's exposure to the two air pollutants that commonly exceed air quality standards: particulate matter (PM10) and nitrogen dioxide $\left(N O_{x}\right)$. In our case, we used Algorithm 2 to compute the daily level of $N O_{x}$.

The algorithm takes as inputs the list of banned vehicles, bannedVehicles, based on their category and Euro class, the operation hours of the LEZ, operationHours, and the emission factors, emissionFactors, which are coefficient parameters used to compute air pollutant emissions.

In Step 1.(a), the vehicle is affected if:

(i) the vehicle category with its Euro class belongs to the list of banned vehicles,

and (ii) the vehicle departure time is within the operation hours of the LEZ,

and (iii) the trip crosses the LEZ (cases 1, 2, 3, and 4).

In Step 1.(b), actions are chosen for each affected vehicle, based on probability distribution $\mathbf{D}_{\text {case }_{i}}$. Table 2 shows the possible actions for each case. Case 5 does not require any action since it corresponds to a trip that does not cross the LEZ. In Section 5, different scenarios include different probabilities.

In Step 1.(c), the distances (in $\mathrm{km}$ ) traveled inside and outside the zone are calculated for each vehicle. If the vehicle is not changing route, the Euclidean distances are used. If the vehicle takes a detour and drive around the LEZ, the number of $\mathrm{km}$ traveled is the sum of two Euclidean distances, that approximate the traveled distances origin-LEZ and LEZ-destination, plus the arc length that approximates the detour.

Step 2.(a) computes, for each hour, the traffic volumes, i.e. the number of vehicles inside and outside the LEZ. The traffic volumes are then used in Eq. 1 to compute the average speed within and outside the LEZ (Step 2.(b)):

$$
\text { speed }_{t}^{I}=f^{I} \times\left(1-\frac{\text { traffic }_{t}^{I}}{\operatorname{Jam}^{I}}\right)^{2}, \quad \text { speed }_{t}^{O}=f^{I} \times\left(1-\frac{\text { traffic }_{t}^{O}}{\operatorname{Jam}^{O}}\right)^{2},
$$




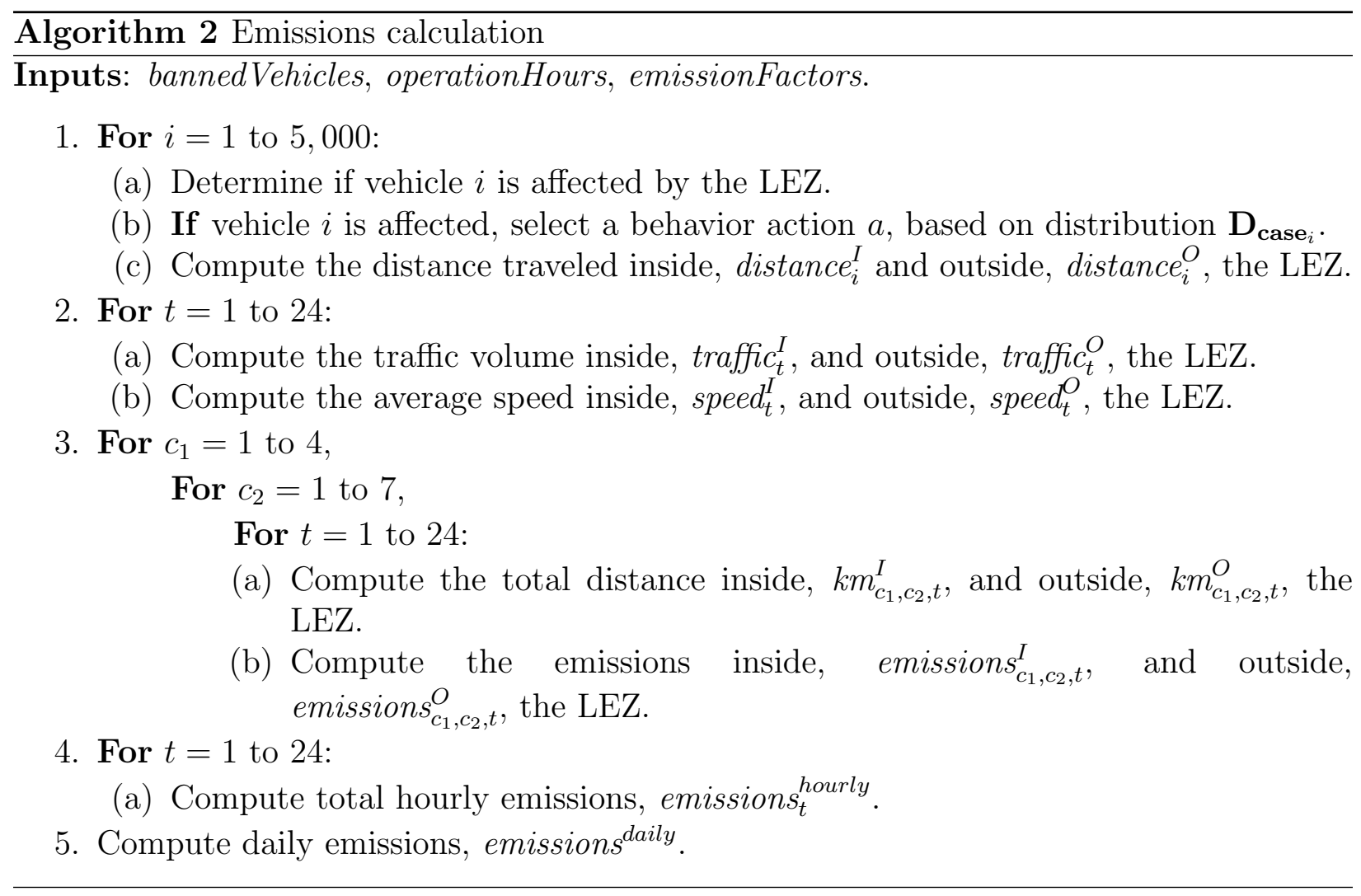

Table 2: List of actions based on road users behavior

\begin{tabular}{cccc}
\hline & $\begin{array}{c}\text { Change } \\
\text { Vehicle } \\
\text { (substitute) }\end{array}$ & $\begin{array}{c}\text { Change } \\
\text { Time }\end{array}$ & $\begin{array}{c}\text { Change } \\
\text { Route } \\
\text { (bypass) }\end{array}$ \\
\hline case 1 & $\checkmark$ & $\checkmark$ & $\boldsymbol{x}$ \\
case 2 & $\checkmark$ & $\checkmark$ & $\boldsymbol{x}$ \\
case 3 & $\checkmark$ & $\checkmark$ & $\boldsymbol{x}$ \\
case 4 & $\checkmark$ & $\checkmark$ & $\checkmark$ \\
\hline
\end{tabular}


where

- $f$ is the free-flow speed, i.e. the average speed if no congestion or adverse conditions.

- traffic is the number of vehicles.

- Jam is the jam density, i.e. the extreme traffic density when traffic flow stops completely.

Step 3.(a) computes the total number of $\mathrm{km}$ traveled within and outside the LEZ, by vehicle category, Euro class, and hour. Step 3.(b) computes by vehicle category, Euro class, and hour, the emissions (in $\mathrm{g} / \mathrm{km}$ ) generated within and outside the LEZ. We followed the MEET procedure (Sturm et al., 1997), a basic, Europe-wide procedure for evaluating the impacts of transport on air pollution. According to MEET, emissions factors are given by Eq. 2. The emission factors used in our experiments are showed in Appendix A.

$$
y_{\left(c_{1}, c_{2}, t\right)}=\frac{k_{c_{1}, c_{2}}\left(a_{c_{1}, c_{2}}+b_{c_{1}, c_{2}} x+c_{c_{1}, c_{2}} x^{2}+d_{c_{1}, c_{2}} x^{3}+e_{c_{1}, c_{2}} x^{4}+f_{c_{1}, c_{2}} x^{5}+g_{c_{1}, c_{2}} x^{6}\right)}{x}
$$

where

- $y$ is the emission factor in $\mathrm{g} / \mathrm{km}$,

- $x$ is the speed in $\mathrm{km} / \mathrm{h}$,

- $k, a, b, c, d, e, f$, and g are emission factors, based on the road vehicle category and Euro class.

Finally, Step 4.(a) and Step 5. compute aggregate levels of emissions (in grams) by hour and day, respectively.

\section{Experimental Results}

In this section, we report on the results of a selection of numerical experiments showing the potential impact of the VAT dimensions and the road users behavior, on emissions. We combine the Vehicle and Time dimensions of the VAT framework leading to nine different restriction rules $(\mathrm{RR})^{3}$. Table 3 gives a structured overview of these rules.

The first three RRs (RR1, RR2, RR3) assume that the LEZ operates 24 hours a day, which corresponds to the vast majority of LEZs, including all German LEZs. Most of the Italian LEZs are exceptions to this rule and are not in operation permanently. These exceptions are captured by the next three RRs (RR4, RR5, RR6) that assume a temporary LEZ, operating from 7AM to 7PM. This is similar to the Milano LEZ Area B. Finally, with the last three RRs (RR7, RR8, RR9), we also consider the LEZs that operate during peak hours only (7AM-10AM and 4PM-7PM). This type of LEZ exists in Islington and Hackney,

\footnotetext{
${ }^{3}$ Notice that an exhaustive experimental design considering all possible design combinations is beyond the scope of this paper.
} 
Table 3: Restriction rules combining Vehicle and Time dimensions

\begin{tabular}{rccc}
\hline & $\begin{array}{c}\text { Only Zero Emission } \\
\text { Vehicles }\end{array}$ & $\begin{array}{c}\text { Only Euro 6 petrol cars } \\
\text { and Euro 3 motorbikes }\end{array}$ & $\begin{array}{c}\text { Only Petrol } \\
\text { Vehicles }\end{array}$ \\
\hline 24 hours & RR1 & RR2 & RR3 \\
7AM to 7PM & RR4 & RR5 & RR6 \\
7AM to 10AM \& 4PM to 7PM & RR7 & RR8 & RR9 \\
\hline
\end{tabular}

two boroughs of Greater London. Regarding the categories of vehicles banned, we have also considered three cases. The first case (RR1, RR4, RR7) assumes a Zero Emission Zone (ZEZ) where only zero-emission vehicles (ZEVs) are allowed. This means that only allelectric vehicles, fully electric public transport vehicles, along with walking and cycling are allowed. The second case (RR2, RR5, RR8) relaxes this assumption by allowing the least polluting petrol vehicles (i.e. the EURO 6 petrol cars and Euro 3 motorbikes) to enter the zone. Finally, the third case represents a diesel vehicle ban, where only petrol vehicles are allowed to enter the zone.

We add the Area dimension of the VAT framework by investigating the impact of these 9 RRs on 3 different LEZ sizes that account for respectively around 15\%,30\%, and $40 \%$ of the area under consideration.

\subsection{Results for combinations of area sizes and $R R$}

Figure 9 shows the distribution of the five possible OD pairs cases (as depicted in Figure 3) for the three area sizes. We observe that the proportions of vehicles starting and/or finishing their trip in the LEZ increase (cases 1-3) when the size of the LEZ increases. On the contrary, the proportions of vehicles crossing (case 4) or whose entire trip is outside the LEZ (case 5) decrease with the LEZ size. Then, whether or not a vehicle in cases 1 to 4 is affected by the LEZ depends on the restriction rule.

Diamond points on Figure 10 indicate the proportion of vehicles affected by each restriction rule for the three area sizes considered. On the same graph, the bars show, for each area size, the emissions produced by the affected vehicles, as a proportion of the total emissions without a LEZ. These emission levels give an idea of the maximum ambition to be realized with an LEZ since, at best, all banned vehicles will be replaced by non-polluting vehicles.

From Figure 10, we can draw three main observations: first, increasing the area of the LEZ leads to larger potential gains. A larger zone logically implies that more vehicles have their trips entirely or partially within the LEZ, and therefore that more vehicles are potentially affected by the ban. For example, $65 \%$ of vehicles are affected by RR1 in Area I while this number increase to $90 \%$ in Area III (cases 1 to 4 in Figure 9). Second, the potential gain is a function of both the operating time and the types of vehicles targeted (grey bar chart). Looking for example at Area II, a temporary ZEZ from 7AM to 7PM (RR4) leads to less potential gains than a permanent ban on all diesel vehicles (RR3). Third, the number of affected vehicles is not proportional to the potential emission gains. For instance, RR6 affects less vehicles than RR7 and RR8, but leads to more emissions gains by specifically targeting vehicles that pollute more. 


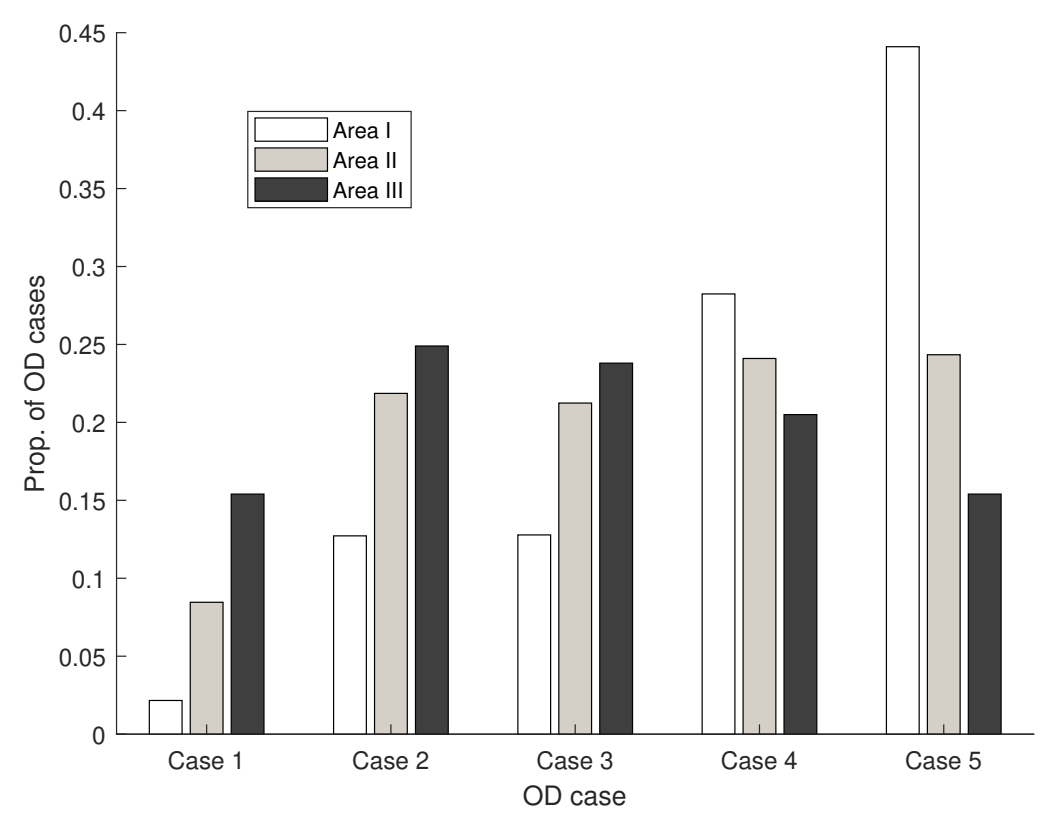

Figure 9-OD pairs cases per area size

\subsection{Results for combinations of $R R$ and $B S$}

In this section, we discuss the emissions gains of the different RRs combined with the different behavior scenarios (see Section 4.3). Again, we normalize our results with respect to the benchmark case of having no LEZ.

\section{Substitution for ZEVs (BS1 and BS2)}

Figure 11 shows the normalized emission levels associated with each RR for BS1 and BS2, and an area size of $30 \%$ (i.e. Area II). Figure 11 (a) gives the total emissions (i.e. emissions inside and outside the LEZ), whereas Figure 11 (b) depicts only the emissions outside the LEZ.

Under BS1, all affected drivers replace their vehicle for a ZEV during the entire trip. The emission levels are thus logically mirroring the maximum emission gains. Under this idealistic (and unrealistic) assumption, we indeed conclude that LEZs are able to achieve substantial reductions in emission levels. Clearly, more restrictive vehicle bans result in higher decreases in emissions.

As expected, under BS2, the emission levels are less reduced than under BS1 since the drivers only substitute their vehicle for a ZEV inside the LEZ. On average, the decrease in emissions for BS2 represents $70 \%$ of the decrease observed in BS1. This comes from the absence of reduction outside the LEZ (see the constant bars corresponding to BS2 on Figure 11 (b)). Similar conclusions can be drawn for Area I and Area III as depicted on Figures 18 and 19 in Appendix B. For these areas, the decrease in emissions for BS2 represents respectively $53 \%$ and $78 \%$ of the decrease observed in BS1.

\section{Impact of bypassing the LEZ}

Under BS3, road users whose trips cross the LEZ (case 4 in Figure 3) choose to bypass the banned area. Figure 12 shows the normalized emission levels associated with BS3 and Area 


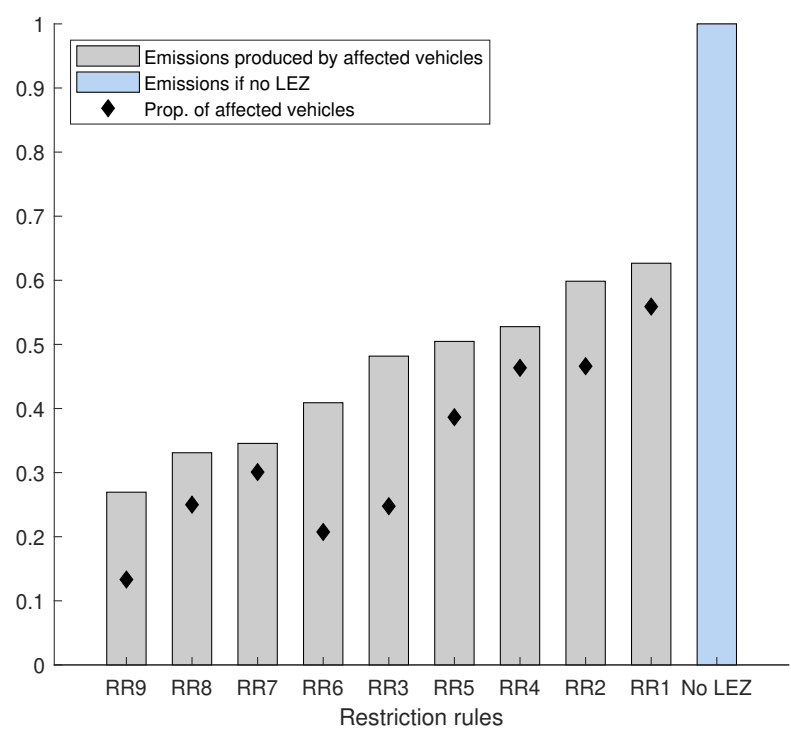

(a) Area I (15\%)

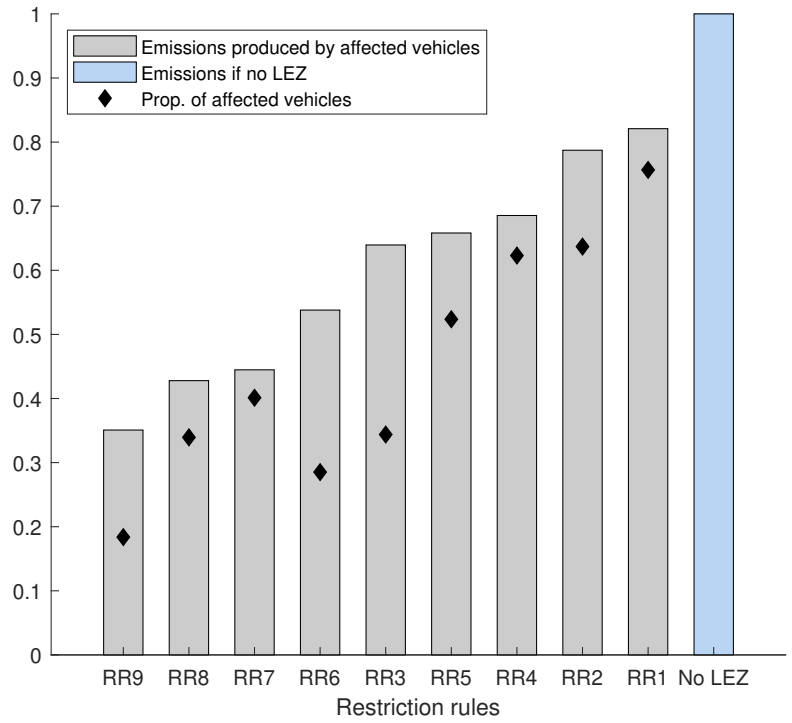

(b) Area II (30\%)

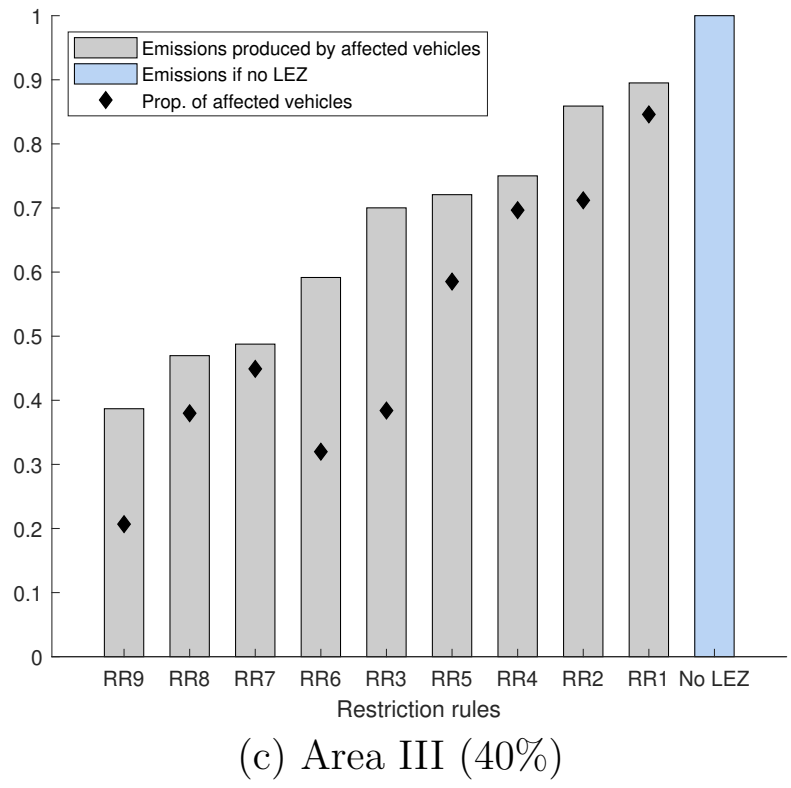

Figure 10-Best achievable impact for each RR and area size 


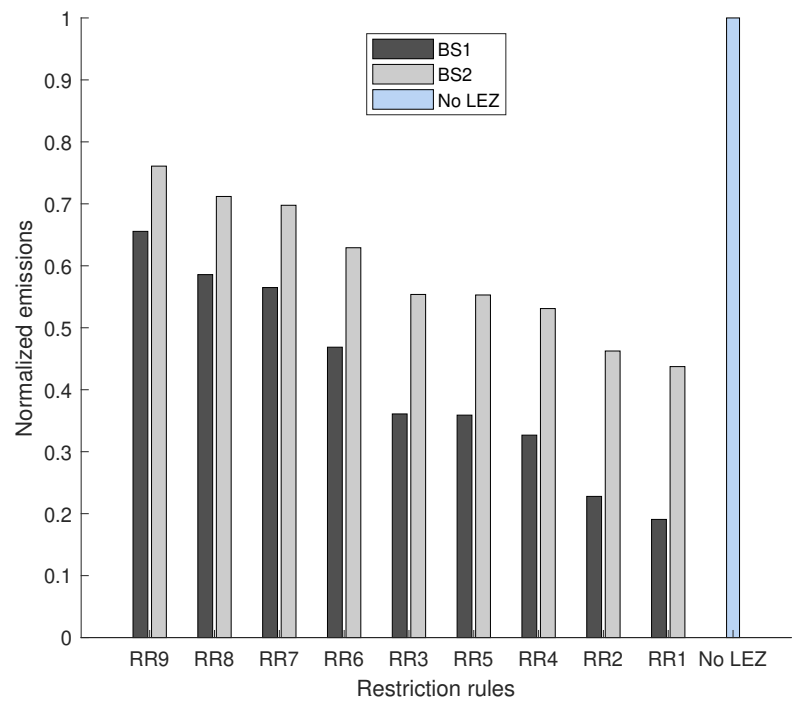

(a) Total emissions

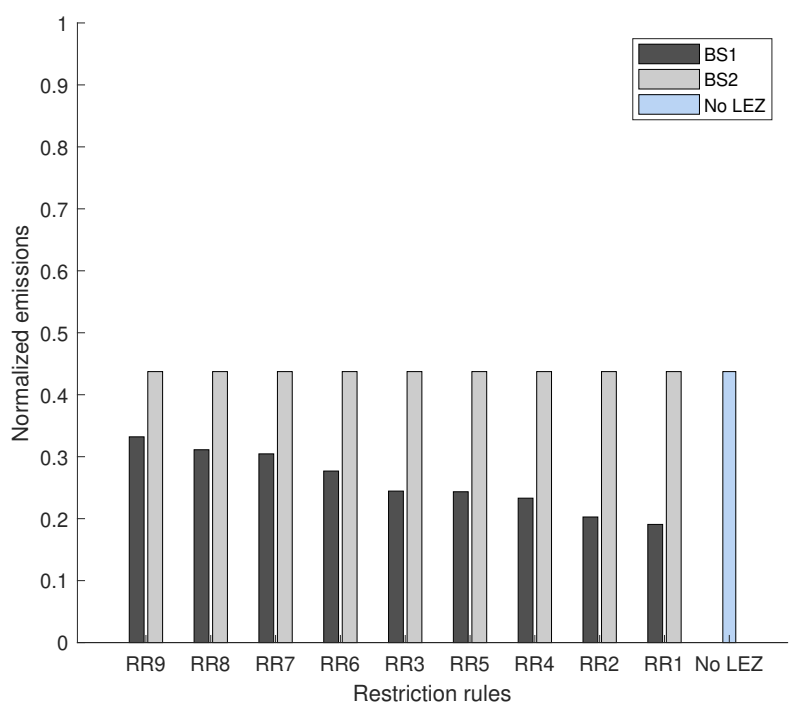

(b) Outside emissions

Figure 11-Comparing BS1 versus BS2 for Area II

II. As illustrated in Figure 12 (a), the total emission levels are less reduced than for BS2. On average, the decrease in emissions for BS3 represents $69 \%$ of the decrease observed in BS2. As showed in Figure 12 (b), this is explained by the increase in emissions outside the LEZ. On average, the outside emissions increase by $30 \%$ from BS2 to BS3. Similar conclusions can be drawn for Area I and Area III as depicted on Figures 20 and 21 of Appendix C. For these areas, the decrease in emissions for BS3 represents respectively $45 \%$ and $74 \%$ of the decrease observed in BS2 and the outside emissions increase by respectively $20 \%$ and $43 \%$ from BS2 to BS3.

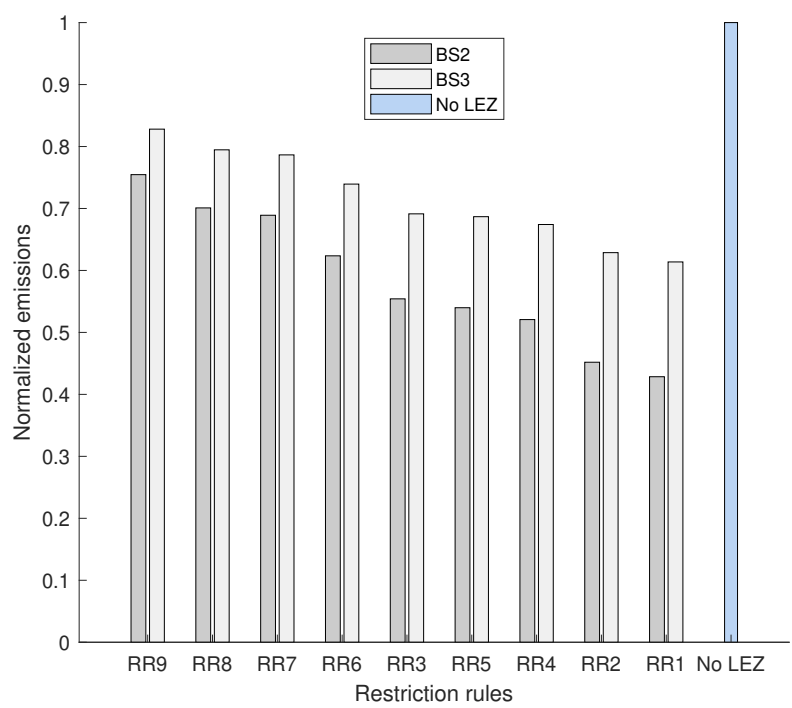

(a) Total emissions

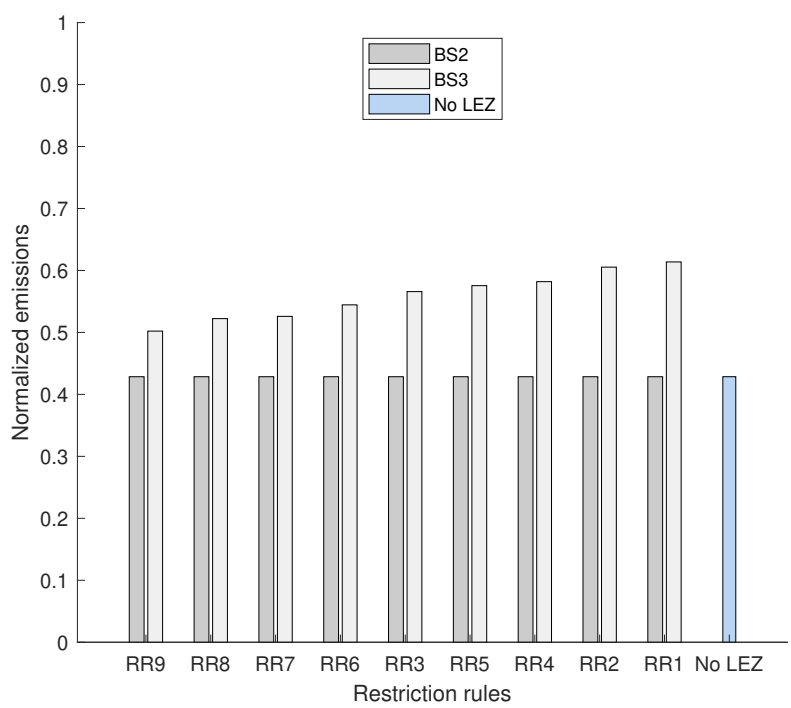

(b) Outside emissions

Figure 12-Impact of bypassing the LEZ for Area II

As depicted in Figure 13 (a), the increases in outside emissions arise from additional dis- 
tance covered by road users who chose to bypass the zone. On average $20 \%$ more kilometers are traveled for Area II. Figure 13 (b) shows that these extra kilometers traveled induce extra emissions, illustrating the importance of including road users' behavior when assessing the effectiveness of LEZs.

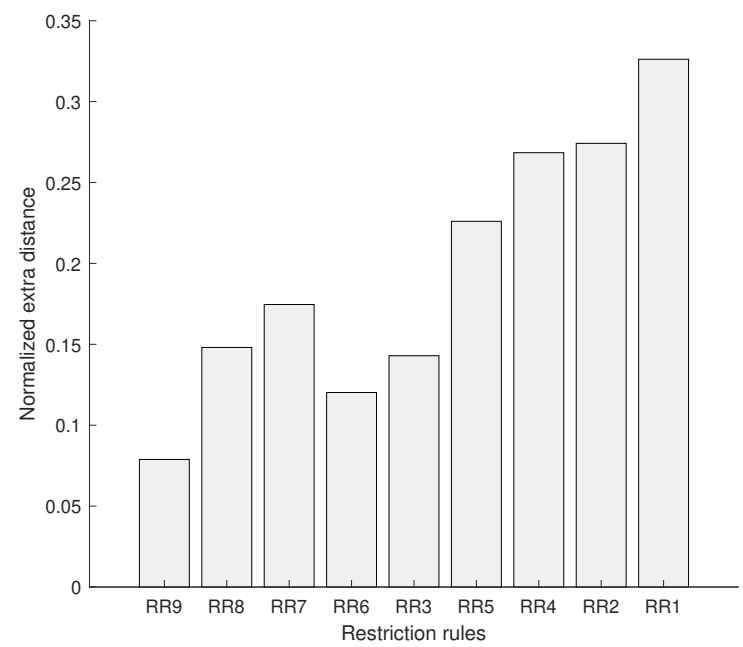

(a) Extra distance

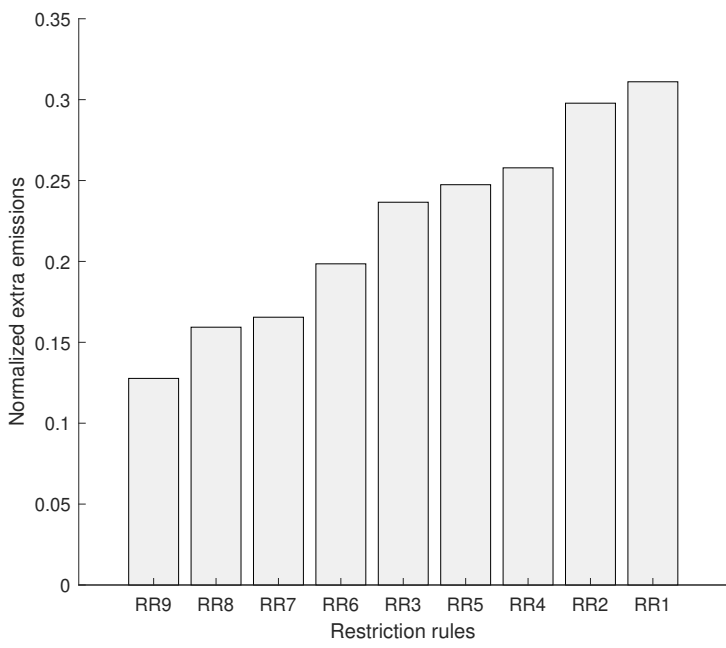

(b) Extra emissions

Figure 13-Impact of bypassing the LEZ for Area II: Extra distance and extra emissions

Corresponding graphs for Area I and III are provided as Figures 22 and 22 in Appendix C. On average $17 \%$ and $18 \%$ more kilometers are traveled outside the zone for Area I and III. The extra-distance driven by drivers bypassing the LEZ is affected by the area size in a non-monotonic way: although an increasing area leads to a larger detour for each vehicle bypassing the zone, the number of those vehicles decreases (as showed in Figure 9). Thus, the total extra-distance (and therefore extra emissions) depends on the interaction between these two effects.

\section{Impact of changing departure time}

Figures 14 (a) and (b) show the normalized emission levels associated with BS4 and BS5 together with Area I and Area II. Since these two scenarios investigate the behavior of changing departure time, only temporary LEZs are analyzed (i.e. RR4-9). We see that the bypassing option considered in BS5 naturally leads to smaller decrease in emissions than BS4. We also see that the emission levels for BS4 are less reduced than for BS2. On average, the decrease in emissions for BS4 represents around $70 \%$ of the decrease observed in BS2, for both Area I and Area II. This comes from the change in behavior of some of the affected drivers that are now assumed to change their travel time rather than substituting their vehicle for a ZEV. Results for Area III are depicted on Figure 24 of Appendix D.

Interestingly, we see that, for Area I and BS5, the three temporary LEZs operating during peak hours (i.e. RR7-9) slightly increase the total emissions compared to the case of no LEZ. The increase in emissions for this behavioral scenario does not only come from an increase in the distance traveled (otherwise it would have been observed for BS3), but also from the 


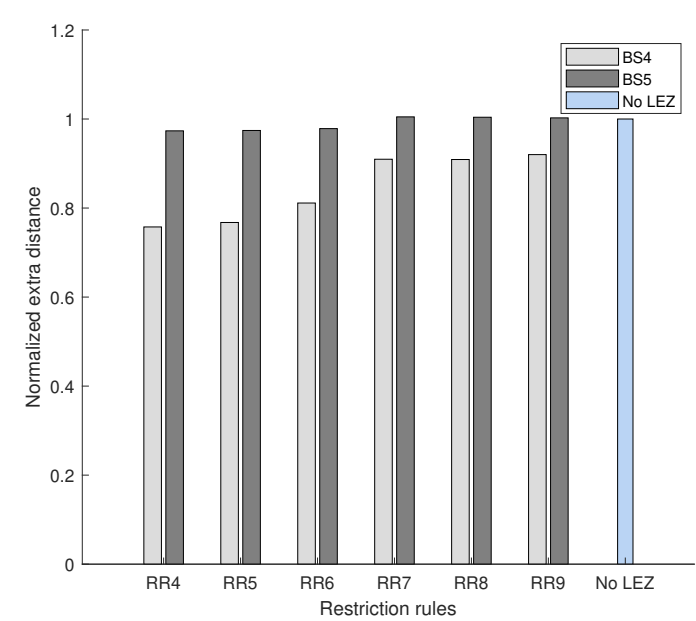

(a) Area I

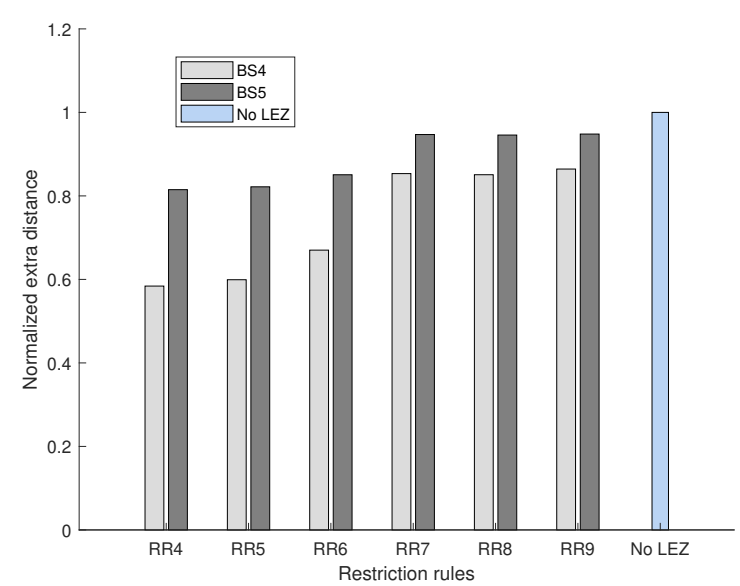

(b) Area II

Figure 14-Impact of changing departure time for Area I and II

cause-and-effect relationship depicted in Eq. (3):

$$
\Delta \text { Departure Time } \Rightarrow \Delta \text { Hourly Traffic Flows } \Rightarrow \Delta \text { Speed } \Rightarrow \Delta \text { Emissions. }
$$

When road users change their departure time, they also modify the hourly traffic volumes within and outside the LEZ at certain times of the day. Figure 15 shows, as an example, the variations in traffic volumes for RR9 coupled with BS5 and Area II. As assumed by BS5, the traffic volumes decrease during the first and last operating hours of the LEZ (i.e. 7AM and $10 \mathrm{AM}$ in the morning and $4 \mathrm{PM}$ and $7 \mathrm{PM}$ in the afternoon) but at the cost of an increase of traffic volumes right before and after these driving bans (i.e. 6AM and 11AM in the morning and $3 \mathrm{PM}$ and $8 \mathrm{PM}$ in the afternoon).

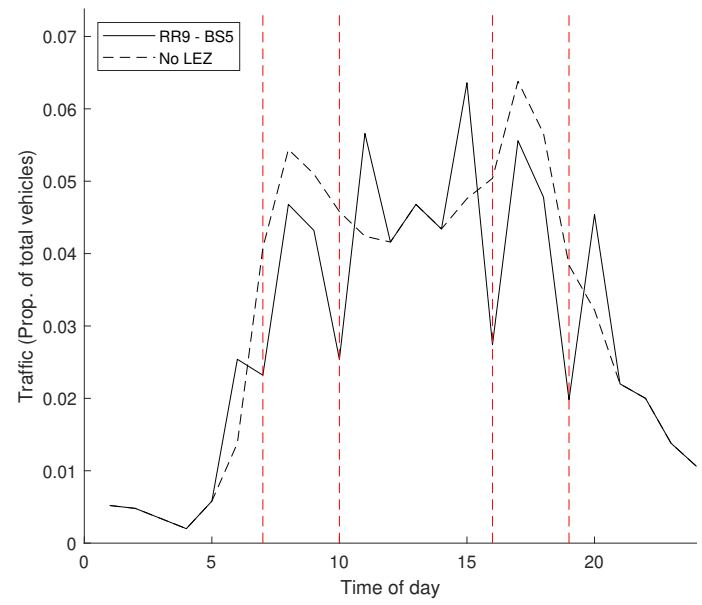

(a) Traffic volume inside

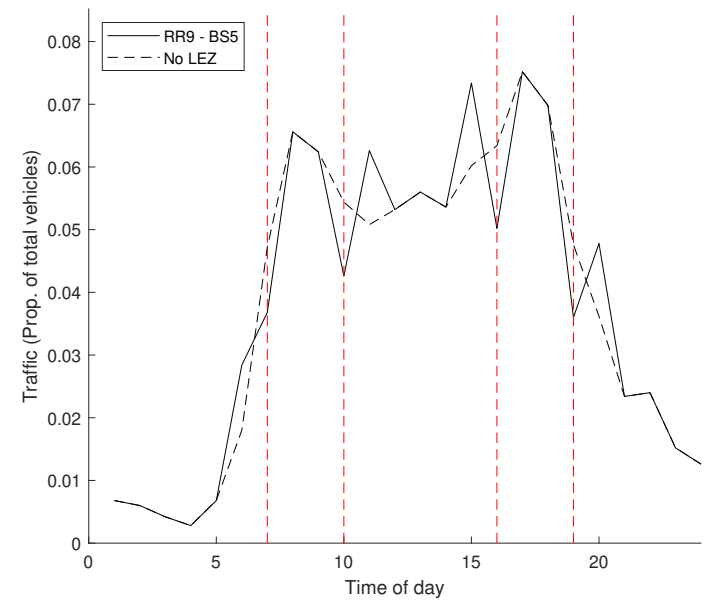

(b) Traffic volume outside

Figure 15-Traffic volume inside and outside the LEZ for RR9, BS5, and Area II

As shown in Figure 16, these changing traffic volumes lead to a change in the (average) speed of vehicles inside and outside the restricted area. Finally, since the inside and outside 
emissions produced by a vehicle also depend on its speed (see Eq. (2)), the change of speed impacts the hourly emissions inside and outside the LEZ, as depicted in Figure 17.

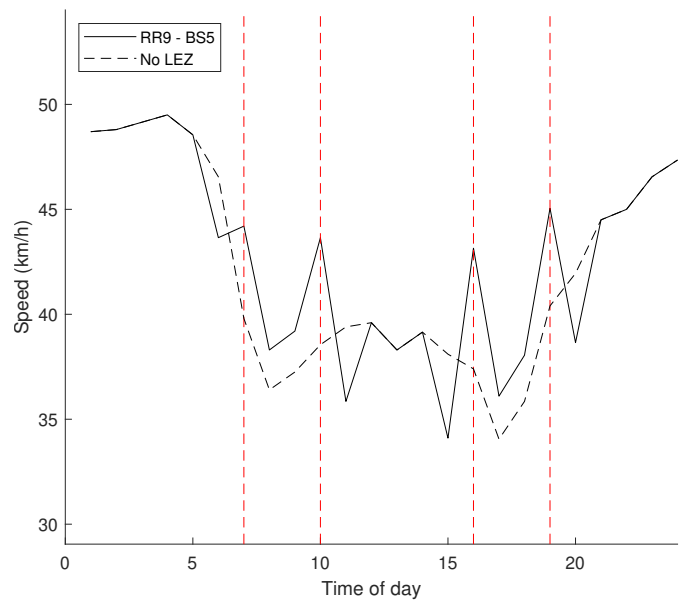

(a) Average speed inside

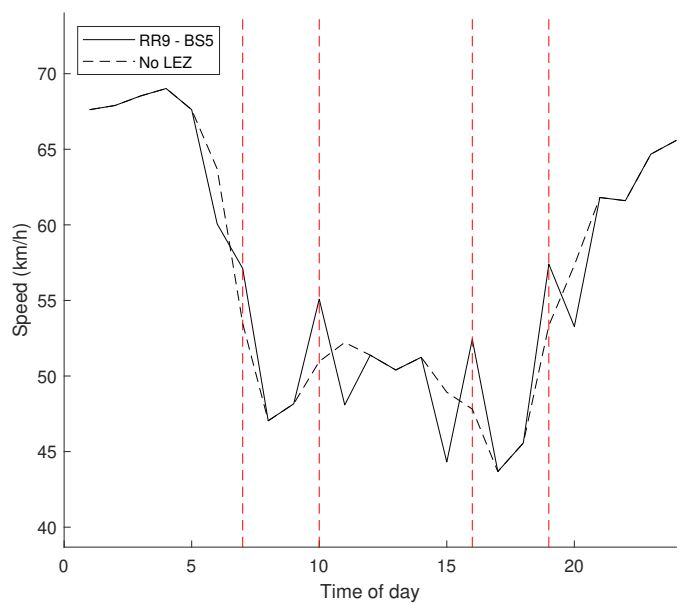

(b) Average speed outside

Figure 16-Average speed inside and outside the LEZ for RR9, BS5, and Area II

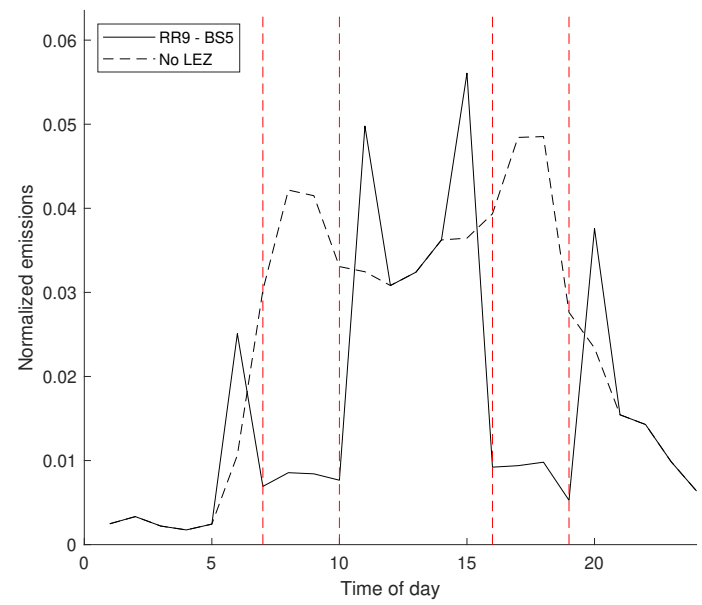

(a) Inside emissions

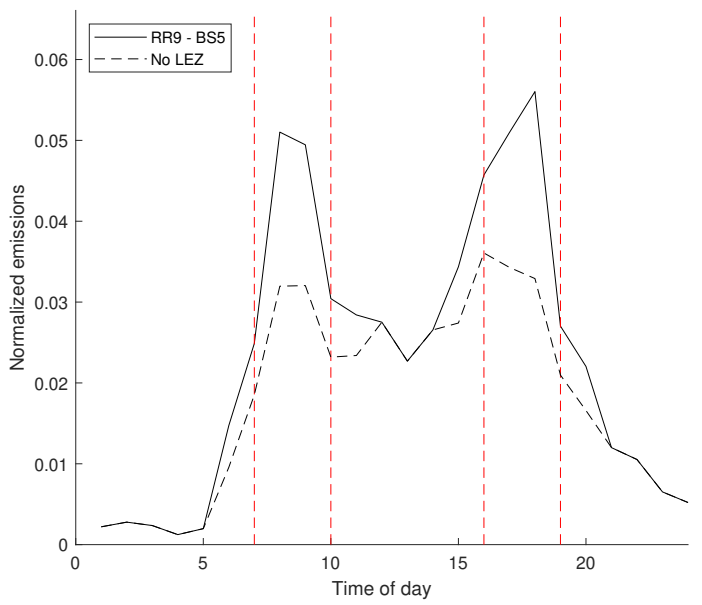

(b) Outside emissions

Figure 17-Emissions inside and outside the LEZ for RR9, BS5, and Area II 


\section{Conclusions and policy implications}

One popular strategy towards sustainable cities consists in setting up Low Emission Zones (LEZs) that regulate or restrict the access to a dedicated urban area, for different classes of polluting vehicles. While LEZs are growing in numbers, there is a lack of understanding regarding how LEZ design and road users' behaviors impact their effectiveness. In this paper, we develop a conceptual framework allowing decision makers to investigate easily a wide range of scenarios including different assumptions related to the Vehicle, Area and Time dimensions of the LEZ, as well as the behaviors of road users. Our analysis highlights that increasing the severity of the operational rules does not necessarily lead to the intended emissions gains. A major reason lies in the negative spillovers associated with the undesired behaviors of road users (e.g., drivers deciding to take detours and drive around the forbidden area). Therefore, there is a need to consider carefully those aspects before establishing the LEZ.

These conclusions foreground several policy implications. First, decision makers should invest sufficiently early in scenario-based analyses before the establishment of any LEZ, with the goal to grasp the interactions between VAT dimensions and behaviors of road users. Second, in order to include realistic behavioral assumptions in their analyses, decision makers should collect comprehensive data documenting behaviors or revealed-behaviors of vehicle users when facing a LEZ. Third, decision makers should consider including several real case studies in their analyses, in close collaborations with cities. This would allow them to use real traffic data, retrieving the essential characteristics of the trips (i.e. the origin, destination, travel distance, speed, and departure time of individual trips), thus going beyond conceptual analyses.

Finally, it is worth noting that a single policy instrument can rarely serve as standalone solution to complex environmental and societal challenges, such as reducing urban air pollution. Therefore, next to banning polluting vehicles to enter specific areas, policy makers should also consider other measures of emission reductions, e.g. road pricing, and investigate the mutual interactions they have with the establishment of a LEZ. 


\section{Appendix}

\section{A. Emission factors used in our experiments.}

Table 4: $N O_{x}$ emission factors for petrol cars and minibus $<2.5$ tonnes GVW with 1400-2000 engine capacity

\begin{tabular}{ccccccccc}
\hline & $\mathrm{K}$ & $\mathrm{a}$ & $\mathrm{b}$ & $\mathrm{c}$ & $\mathrm{d}$ & $\mathrm{e}$ & $\mathrm{f}$ & $\mathrm{g}$ \\
\hline Euro 1 & 1.00 & $2.37 \mathrm{E}+00$ & $1.99 \mathrm{E}-01$ & $6.47 \mathrm{E}-04$ & $3.22 \mathrm{E}-06$ & 0 & 0 & 0 \\
Euro 2 & 1.00 & $1.10 \mathrm{E}+00$ & $1.20 \mathrm{E}-01$ & $6.13 \mathrm{E}-04$ & $1.17 \mathrm{E}-06$ & $8.78 \mathrm{E}-09$ & 0 & 0 \\
Euro 3 & 1.00 & $4.37 \mathrm{E}-01$ & $6.14 \mathrm{E}-02$ & $8.02 \mathrm{E}-05$ & $8.83 \mathrm{E}-08$ & 0 & 0 & 0 \\
Euro 4 & 1.00 & $5.17 \mathrm{E}-01$ & $3.45 \mathrm{E}-02$ & $5.49 \mathrm{E}-05$ & $4.08 \mathrm{E}-07$ & 0 & 0 & 0 \\
Euro 5 & 0.594 & $5.17 \mathrm{E}-01$ & $3.45 \mathrm{E}-02$ & $5.49 \mathrm{E}-05$ & $4.08 \mathrm{E}-07$ & 0 & 0 & 0 \\
Euro 6 & 0.594 & $5.17 \mathrm{E}-01$ & $3.45 \mathrm{E}-02$ & $5.49 \mathrm{E}-05$ & $4.08 \mathrm{E}-07$ & 0 & 0 & 0 \\
\hline
\end{tabular}

Table 5: $N O_{x}$ emission factors for diesel cars and minibus $<2.5$ tonnes GVW with 1400-2000 engine capacity

\begin{tabular}{|c|c|c|c|c|c|c|c|c|}
\hline & $\mathrm{K}$ & $\mathrm{a}$ & $\mathrm{b}$ & $\mathrm{c}$ & $\mathrm{d}$ & $\mathrm{e}$ & $\mathrm{f}$ & g \\
\hline Euro 1 & 1.00 & $1.12 \mathrm{E}+01$ & $1.58 \mathrm{E}-01$ & $1.24 \mathrm{E}-03$ & $2.27 \mathrm{E}-05$ & $-8.30 \mathrm{E}-08$ & 1.09E-09 & 0 \\
\hline Euro 2 & 1.00 & $1.48 \mathrm{E}+01$ & $1.77 \mathrm{E}-01$ & $-3.00 \mathrm{E}-04$ & $6.43 \mathrm{E}-05$ & $-4.62 \mathrm{E}-07$ & $2.96 \mathrm{E}-09$ & 0 \\
\hline Euro 3 & 1.00 & $9.29 \mathrm{E}+00$ & $1.68 \mathrm{E}-01$ & $1.18 \mathrm{E}-03$ & $1.50 \mathrm{E}-05$ & $-3.75 \mathrm{E}-08$ & $4.97 \mathrm{E}-10$ & 0 \\
\hline Euro 4 & 1.00 & $5.49 \mathrm{E}+00$ & $1.23 \mathrm{E}-01$ & $6.71 \mathrm{E}-04$ & $2.08 \mathrm{E}-05$ & $-9.97 \mathrm{E}-08$ & $8.50 \mathrm{E}-10$ & 0 \\
\hline Euro 5 & 0.675 & $5.49 \mathrm{E}+00$ & $1.23 \mathrm{E}-01$ & 6.71E-04 & $2.08 \mathrm{E}-05$ & $-9.97 \mathrm{E}-08$ & $8.50 \mathrm{E}-10$ & 0 \\
\hline Euro 6 & 0.3 & $5.49 \mathrm{E}+00$ & $1.23 \mathrm{E}-01$ & $6.71 \mathrm{E}-04$ & $2.08 \mathrm{E}-05$ & $-9.97 \mathrm{E}-08$ & $8.50 \mathrm{E}-10$ & 0 \\
\hline
\end{tabular}

Table 6: $N O_{x}$ emission factors for diesel light goods/commercial vehicles

\begin{tabular}{|c|c|c|c|c|c|c|c|c|}
\hline & K & $\mathrm{a}$ & b & c & $\mathrm{d}$ & $\mathrm{e}$ & $\mathrm{f}$ & g \\
\hline Euro 1 & 1.00 & $1.90 \mathrm{E}+01$ & $1.23 \mathrm{E}-01$ & $-2.18 \mathrm{E}-03$ & $1.06 \mathrm{E}-04$ & $-1.06 \mathrm{E}-06$ & $6.74 \mathrm{E}-09$ & 0 \\
\hline Euro 2 & 1.00 & $1.84 \mathrm{E}+01$ & $1.95 \mathrm{E}-01$ & $5.60 \mathrm{E}-04$ & $4.83 \mathrm{E}-05$ & $-2.93 \mathrm{E}-07$ & 2.13E-09 & 0 \\
\hline Euro 3 & 1.00 & $1.59 \mathrm{E}+01$ & $1.15 \mathrm{E}-01$ & 1.79E-04 & $4.42 \mathrm{E}-05$ & $-3.33 \mathrm{E}-07$ & $2.66 \mathrm{E}-09$ & 0 \\
\hline Euro 4 & 0.50 & $1.59 \mathrm{E}+01$ & $1.15 \mathrm{E}-01$ & $1.79 \mathrm{E}-04$ & $4.42 \mathrm{E}-05$ & $-3.33 \mathrm{E}-07$ & $2.66 \mathrm{E}-09$ & 0 \\
\hline Euro 5 & 0.334 & $1.59 \mathrm{E}+01$ & $1.15 \mathrm{E}-01$ & $1.79 \mathrm{E}-04$ & $4.42 \mathrm{E}-05$ & $-3.33 \mathrm{E}-07$ & 2.66E-09 & 0 \\
\hline Euro 6 & 0.149 & $1.59 \mathrm{E}+01$ & $1.15 \mathrm{E}-01$ & $1.79 \mathrm{E}-04$ & $4.42 \mathrm{E}-05$ & $-3.33 \mathrm{E}-07$ & $2.66 \mathrm{E}-09$ & 0 \\
\hline
\end{tabular}

Table 7: $N O_{x}$ emission factors for motorcycle with 150-250 engine capacity (cc)

\begin{tabular}{ccccccccc}
\hline & $\mathrm{K}$ & $\mathrm{a}$ & $\mathrm{b}$ & $\mathrm{c}$ & $\mathrm{d}$ & $\mathrm{e}$ & $\mathrm{f}$ & $\mathrm{g}$ \\
\hline Euro 1 & 1.00 & $-4.21 \mathrm{E}-07$ & $2.95 \mathrm{E}-01$ & $-9.01 \mathrm{E}-03$ & $3.49 \mathrm{E}-04$ & $-4.81 \mathrm{E}-06$ & $3.31 \mathrm{E}-08$ & $-8.69 \mathrm{E}-11$ \\
Euro 2 & 1.00 & $-4.21 \mathrm{E}-07$ & $2.95 \mathrm{E}-01$ & $-9.01 \mathrm{E}-03$ & $3.49 \mathrm{E}-04$ & $-4.81 \mathrm{E}-06$ & $3.31 \mathrm{E}-08$ & $-8.69 \mathrm{E}-11$ \\
Euro 3 & 1.00 & $-2.14 \mathrm{E}-07$ & $1.57 \mathrm{E}-01$ & $-4.92 \mathrm{E}-03$ & $1.81 \mathrm{E}-04$ & $-2.43 \mathrm{E}-06$ & $1.63 \mathrm{E}-08$ & $-4.22 \mathrm{E}-11$ \\
\hline
\end{tabular}




\section{B. Results of BS1 and BS2 for Area I and III}

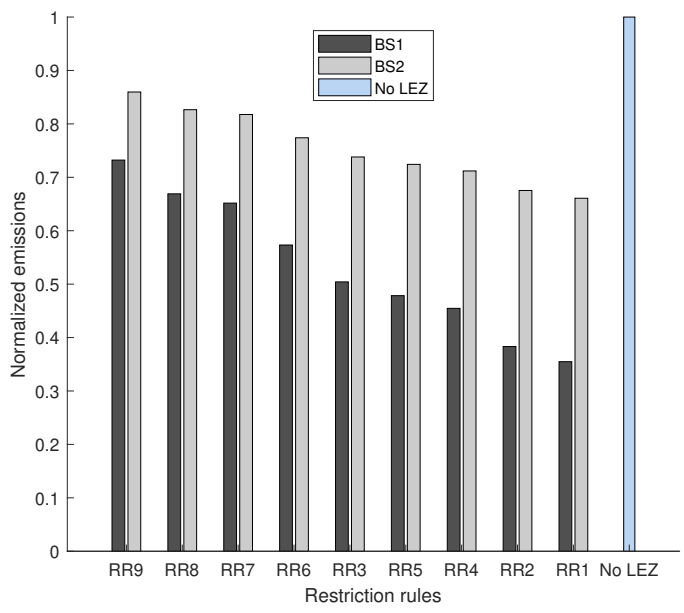

(a) Total emissions

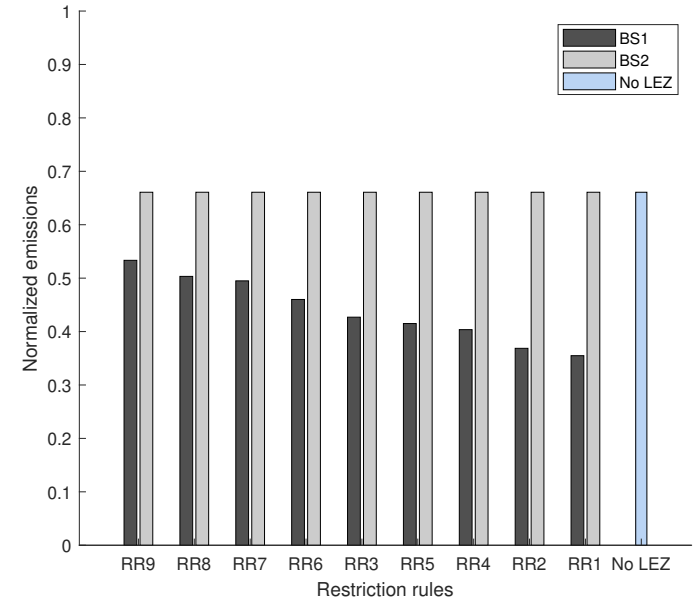

(b) Outside emissions

Figure 18-Comparing BS1 versus BS2 for Area I

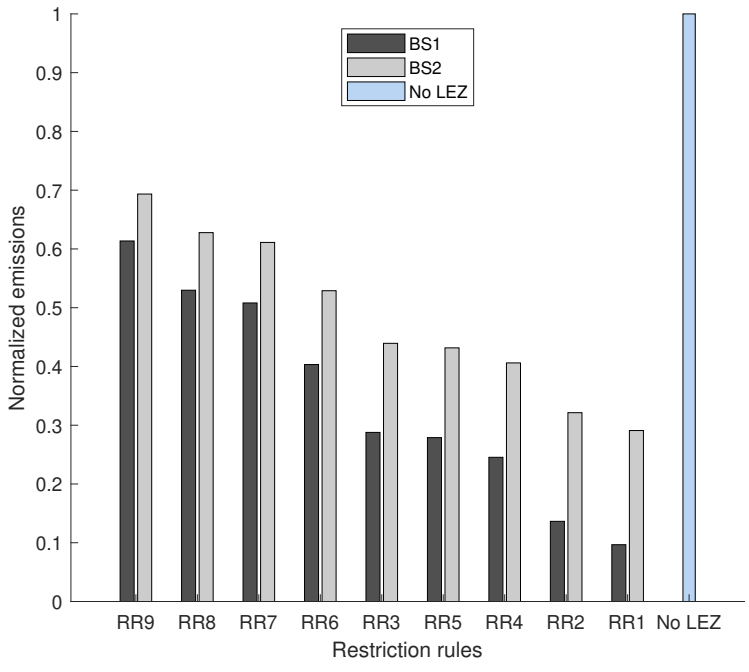

(a) Total emissions

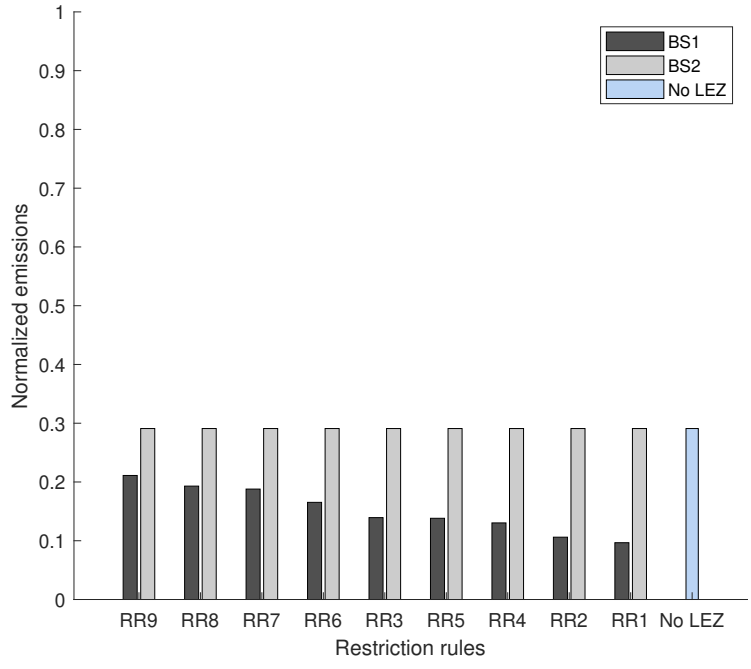

(b) Outside emissions

Figure 19-Comparing BS1 versus BS2 for Area III 


\section{Results of BS2 and BS3 for Area I and III}

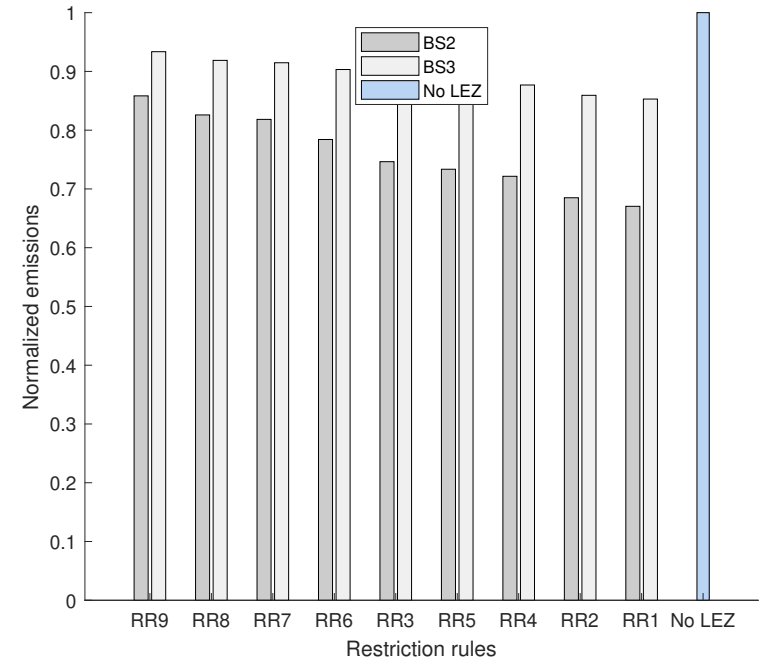

(a) Total emissions

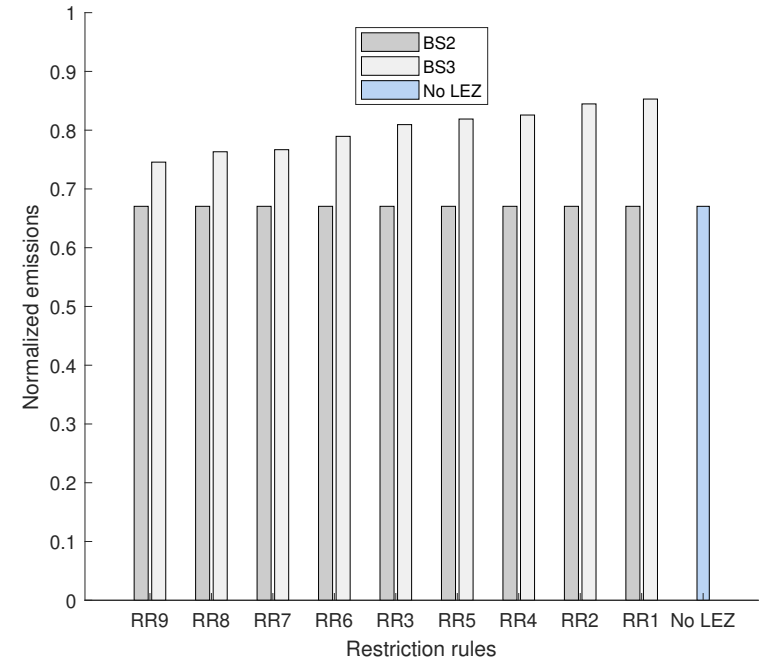

(b) Outside emissions

Figure 20 - Comparing BS2 versus BS3 for Area I

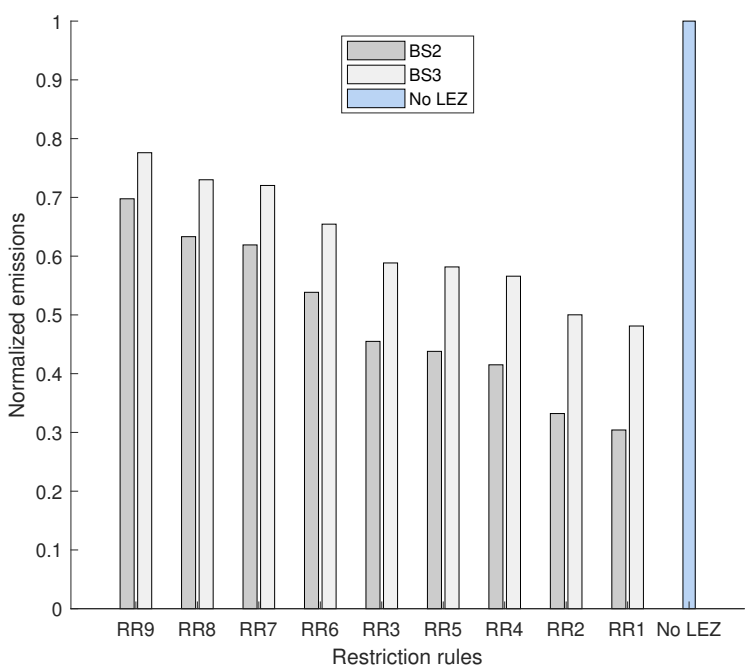

(a) Total emissions

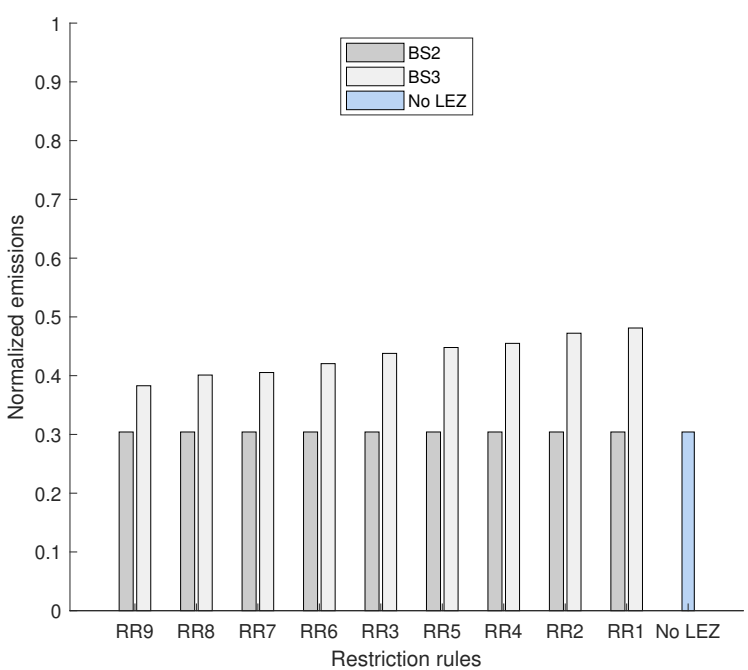

(b) Outside emissions

Figure 21-Comparing BS2 versus BS3 for Area III 


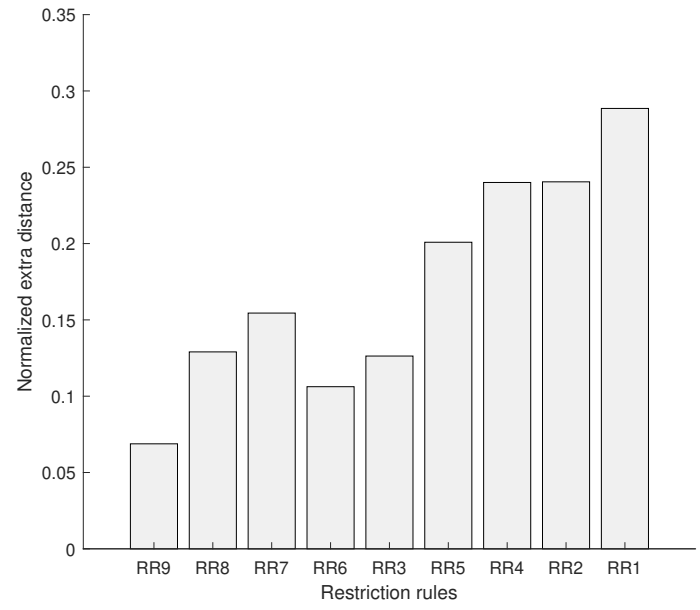

(a) Extra distance

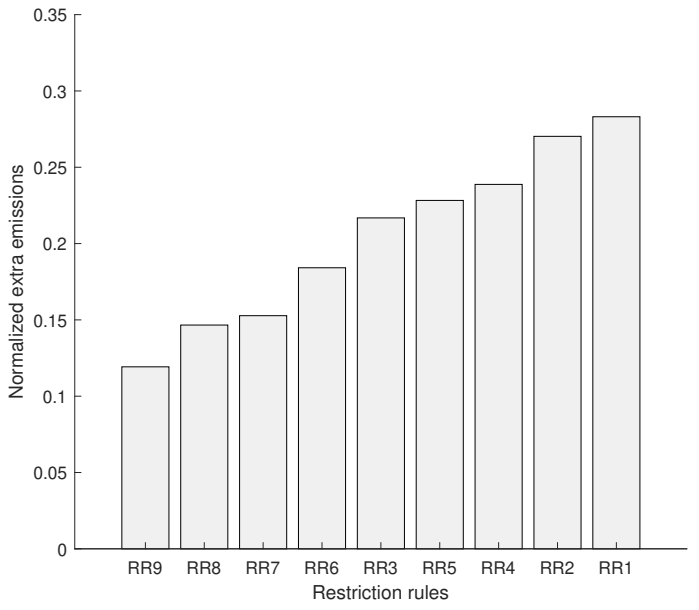

(b) Extra emissions

Figure 22-Impact of bypassing the LEZ for Area I: Extra distance and extra emissions

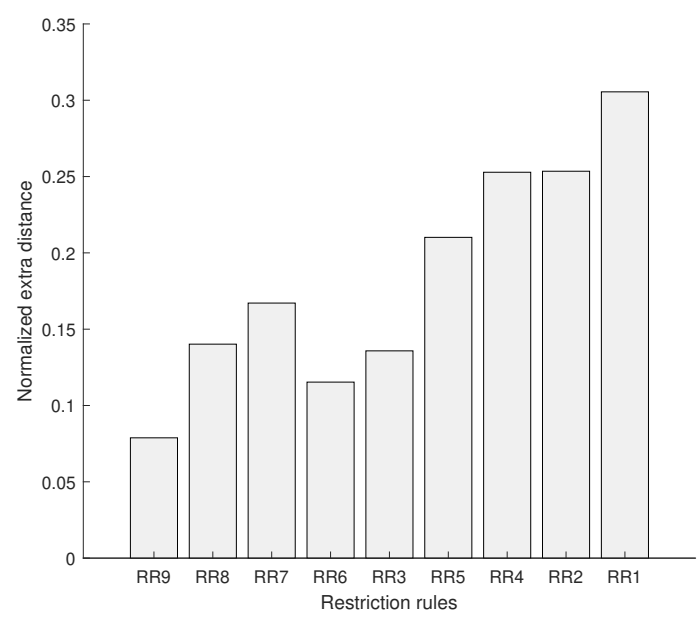

(a) Extra distance

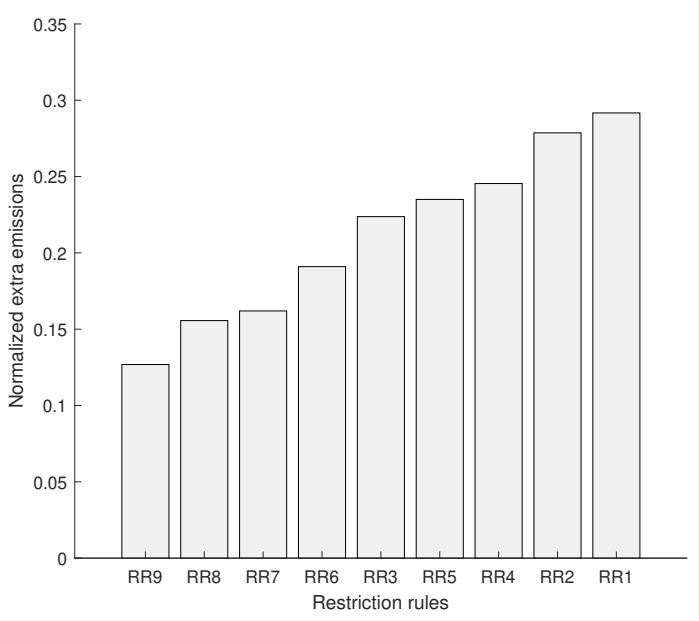

(b) Extra emissions

Figure 23-Impact of bypassing the LEZ for Area III: Extra distance and extra emissions 
D. Results of BS4 and BS5 for Area III

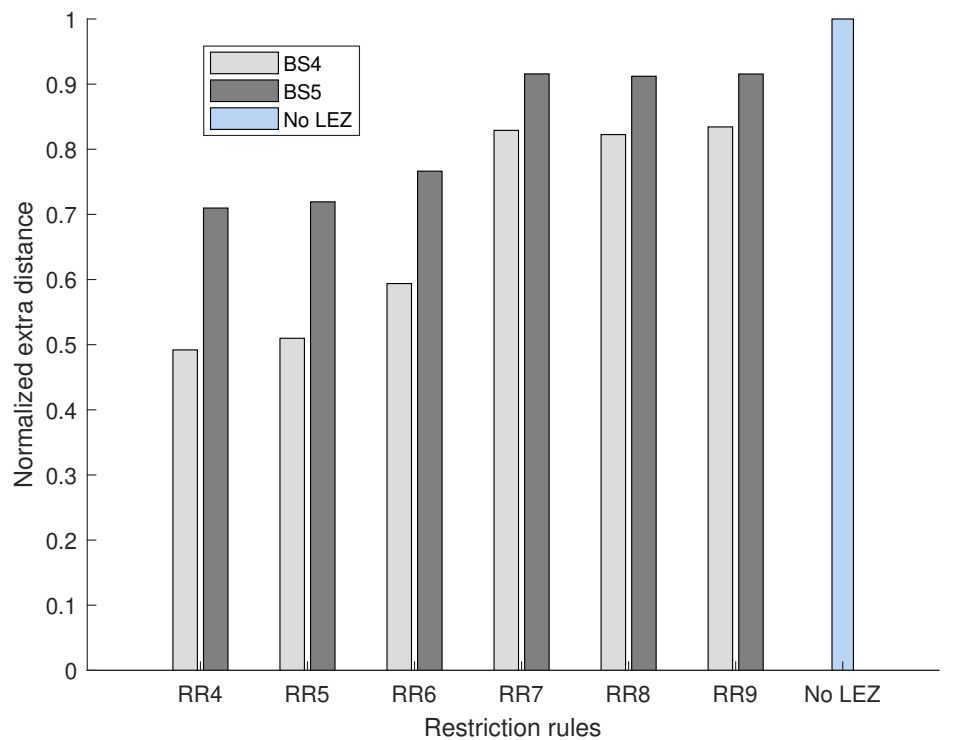

Figure 24-Total emissions for BS4 and BS5 and Area III 


\section{References}

Urban access regulations in europe. https://urbanaccessregulations . eu/low-emission-zones-main. Accessed: 2019-08-28.

ACEA. Acea report vehicles in use europe 2018, 2018.

M. André, M. Carteret, A. Pasquier, and Y. Liu. Methodology for characterizing vehicle fleet composition and its territorial variability, needed for assessing low emission zones. Transportation Research Procedia, 25:3286-3298, 2017. World Conference on Transport Research - WCTR 2016 Shanghai. 10-15 July 2016.

H. Boogaard, N. A. Janssen, P. H. Fischer, G. P. Kos, E. P. Weijers, F. R. Cassee, S. C. van der Zee, J. J. de Hartog, K. Meliefste, M. Wang, B. Brunekreef, and G. Hoek. Impact of low emission zones and local traffic policies on ambient air pollution concentrations. Science of The Total Environment, 435-436:132-140, 2012.

B. D. Borger and S. Proost. Traffic externalities in cities: The economics of speed bumps, low emission zones and city bypasses. Journal of Urban Economics, 76:53-70, 2013.

D. Carslaw and S. Beevers. The efficacy of low emission zones in central london as a means of reducing nitrogen dioxide concentrations. Transportation Research Part D: Transport and Environment, 7(1):49-64, 2002.

R. Ellison, S. Greaves, and D. Hensher. Five years of london's low emission zone: Effects on vehicle fleet composition and air quality. Transportation Research Part D: Transport and Environment, 23:25-33, 2013.

V. Fensterer, H. Küchenhoff, V. Maier, H.-E. Wichmann, S. Breitner, A. Peters, J. Gu, and J. Cyrys. Evaluation of the impact of low emission zone and heavy traffic ban in munich (germany) on the reduction of pm10 in ambient air. International Journal of Environmental Research and Public Health, 11(5):5094-5112, May 2014.

F. Ferreira, P. Gomes, H. Tente, A. Carvalho, P. Pereira, and J. Monjardino. Air quality improvements following implementation of lisbon's low emission zone. Atmospheric Environment, 122:373 - 381, 2015.

H. Flämig, S. Lunkeit, K. Rosenberger, and J. Wolff. Enlarging the scale of bevs through environmental zoning to reduce ghg emissions: A case study for the city of hamburg. Research in Transportation Business \& Management, page 100418, 2019.

R. Haakman, I. Beenakker, and H. Geerlings. Reducing vehicle-related nox and pm emissions in metropolitan areas: A comparison between the randstad and the rhine-ruhr area. Journal of Cleaner Production, 247:119-175, 2020.

C. Holman, R. Harrison, and X. Querol. Review of the efficacy of low emission zones to improve urban air quality in european cities. Atmospheric Environment, 111:161-169, 2015. 
W. Jiang, M. Boltze, S. Groer, and D. Scheuvens. Impacts of low emission zones in germany on air pollution levels. Transportation Research Procedia, 25:3370 - 3382, 2017. World Conference on Transport Research - WCTR 2016 Shanghai. 10-15 July 2016.

M. Leonhart. Environmental and social effects of the rotterdam low emission zone: an empirical approach, 2017.

U. Nations. 2018 revision of world urbanization prospects, 2018.

A. Pasquier and M. Andre. Decomposition of low emission zone strategies into mechanisms and methodology for assessing their impacts on air pollution. Journal of Earth Sciences and Geotechnical Engineering, 7(1), 2017.

S. Pelletier, O. Jabali, and G. Laporte. Goods distribution with electric vehicles: review and research perspectives. Transportation Science, 50(1):3-22, 2016.

H. Quak and M. de Koster. Delivering goods in urban areas: how to deal with urban policy restrictions and the environment. Transportation science, 43(2):211-227, 2009.

F. Santos, Á. Gómez-Losada, and J. Pires. Impact of the implementation of lisbon low emission zone on air quality. Journal of hazardous materials, 365:632-641, 2019.

M. Savelsbergh and T. Van Woensel. City logistics: Challenges and opportunities. Transportation Science, 50(2):579-590, 2016.

P. Stopher and J. Stanley. Introduction to Transport Policy: A Public Policy View. Edward Elgar Publishing, 2014.

P. Sturm, G. Schinagl, S. Hausberger, C. Reiter, and R. Pischinger. Instantaneous emission data and their use in estimating passenger car emissions, 1997.

The European Commission. Study on Urban Vehicle Access Regulations. The European Commission, $2017 . \quad$ URL https://ec . europa.eu/transport/sites/transport/files/uvar inal $_{r}$ eport $_{a}$ ugust ${ }_{2}$ 8.pdf. 